\title{
CHANGE IN LIFE ROLES AND QUALITY OF LIFE IN OLDER ADULTS AFTER
}

TRAUMATIC BRAIN INJURY

\author{
A thesis submitted in partial fulfilment \\ of the requirements for the degree of \\ Master of Science in Psychology
}

\section{Katie Joanne Dainter}

University of Canterbury

2016 


\section{Contents}

Contents.

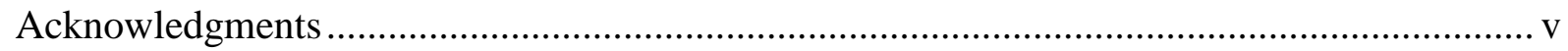

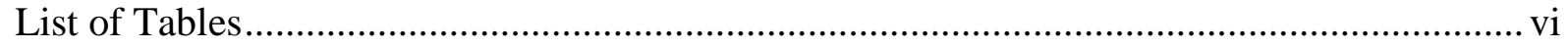

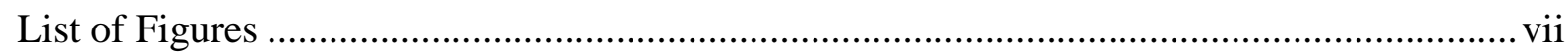

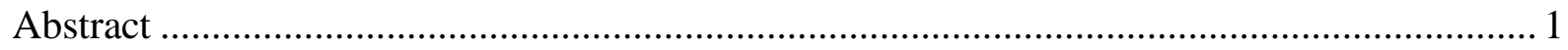

1 Introduction

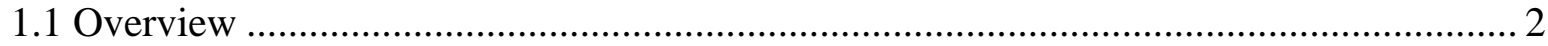

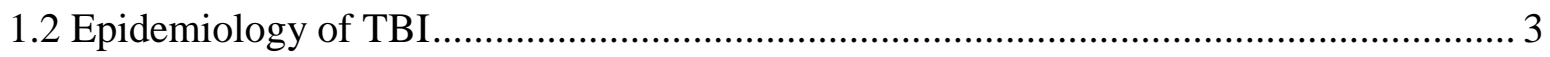

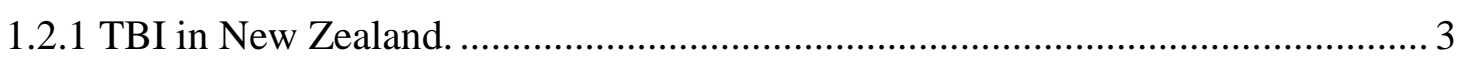

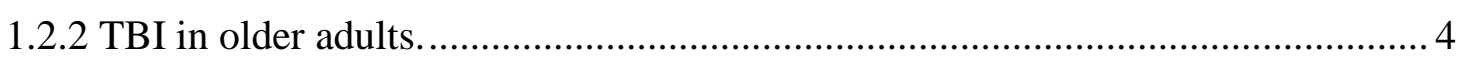

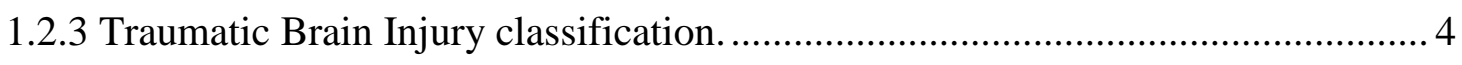

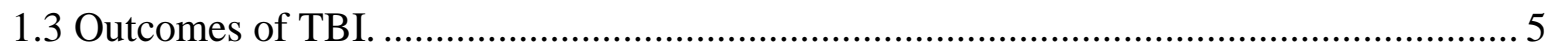

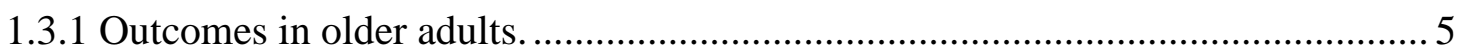

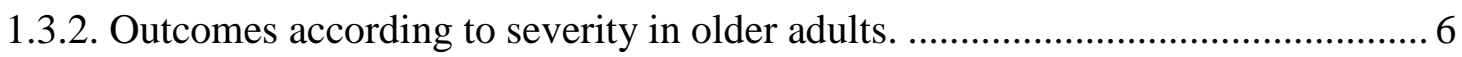

1.4 Effect of TBI on return to work............................................................................ 7

1.4.1 Effect of TBI on return to work for all age groups............................................. 7

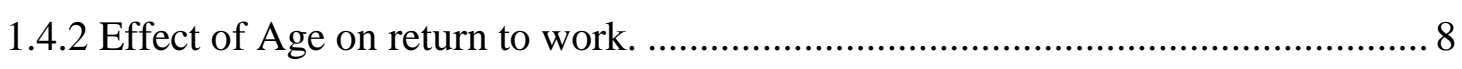

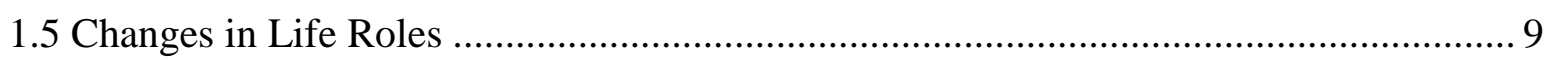

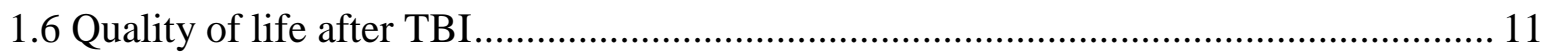

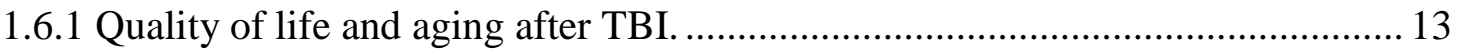

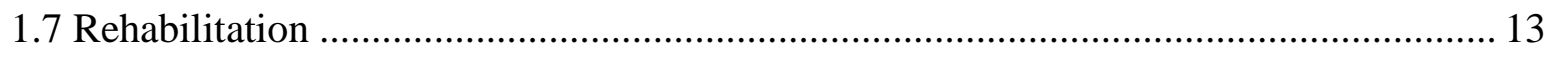

1.7.2 Outcomes after rehabilitation in older adults. ............................................... 14

1.7.3 Perceptions of rehabilitative services available................................................. 15

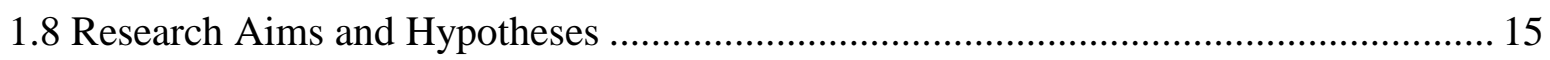

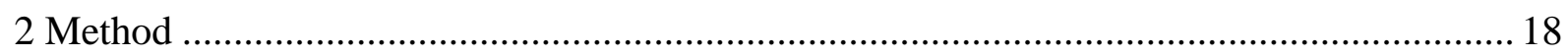

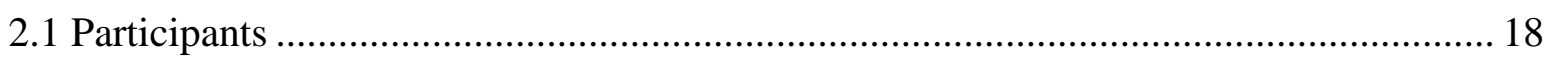

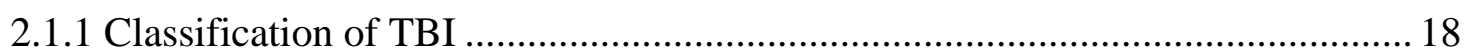

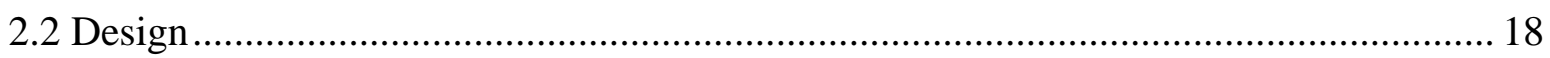

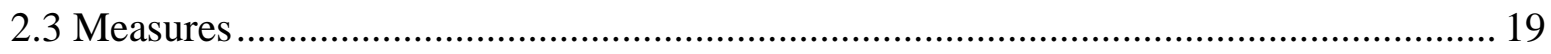

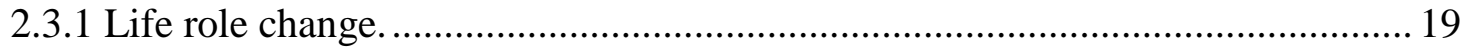

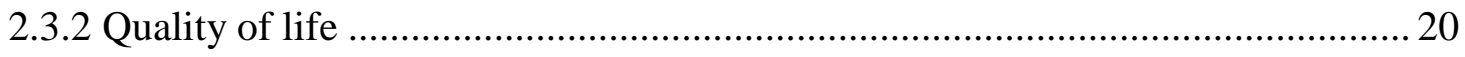

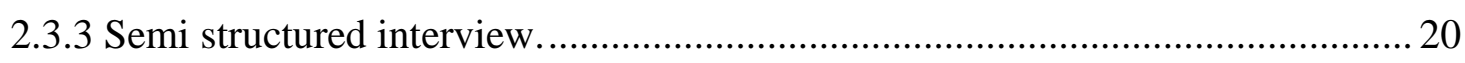

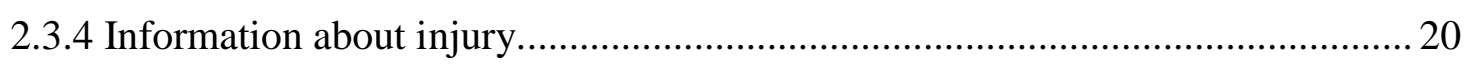

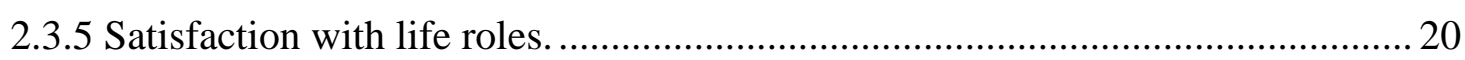




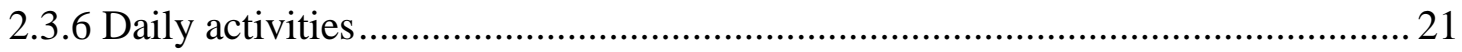

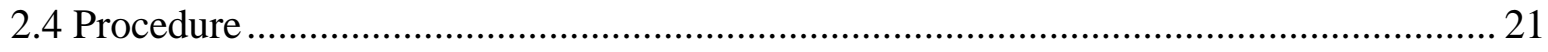

2.4.1 Interview Procedure

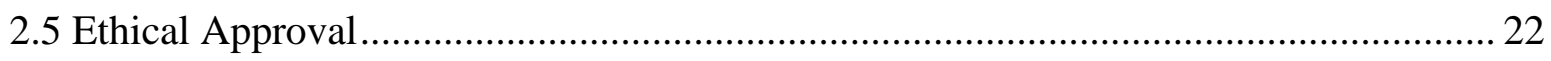

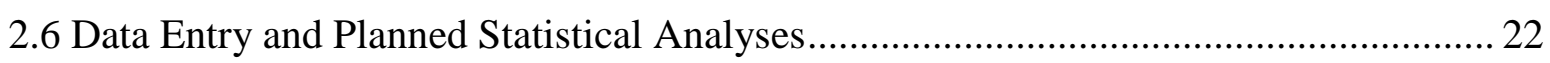

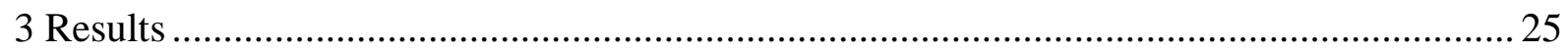

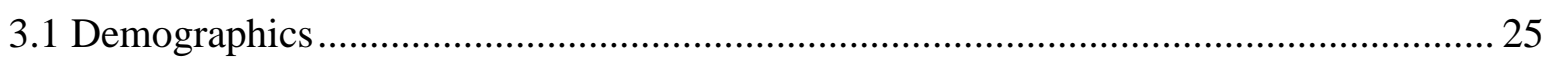

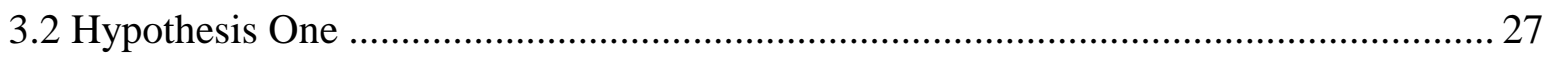

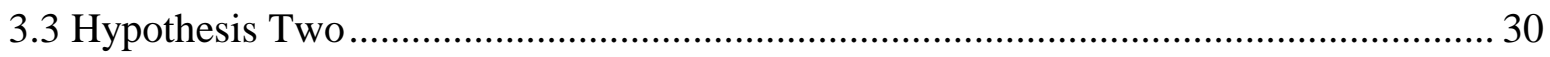

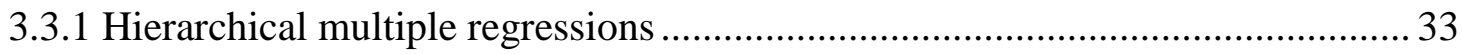

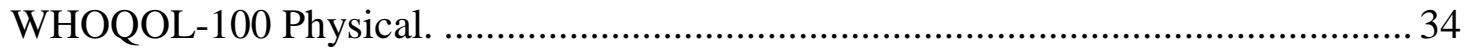

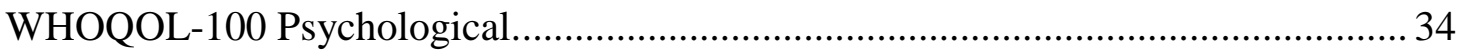

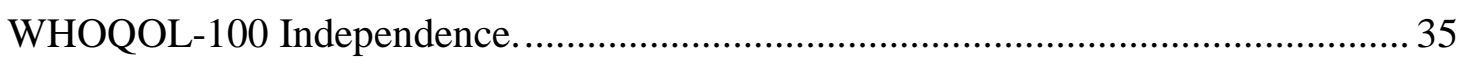

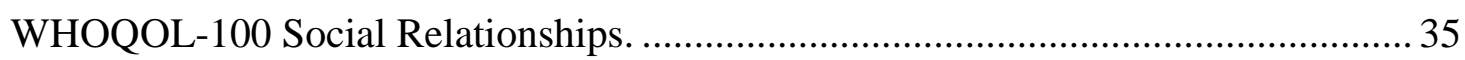

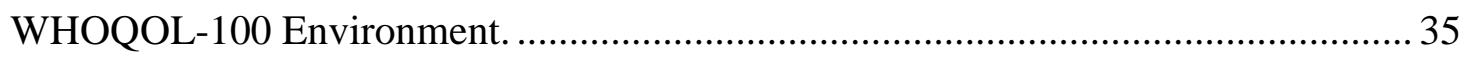

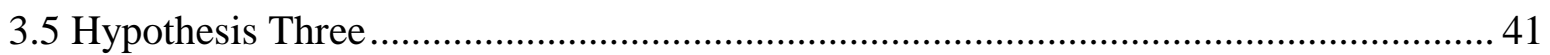

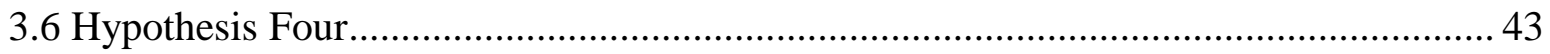

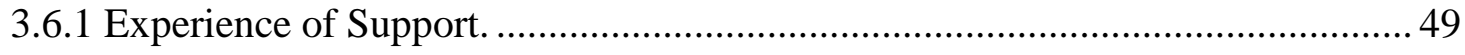

3.6.2 Perceived understanding and empathy around symptoms..................................53

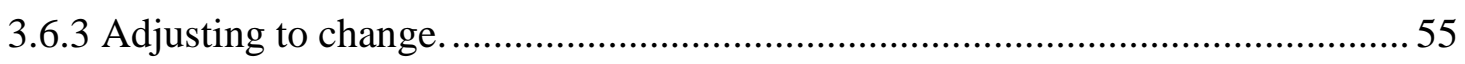

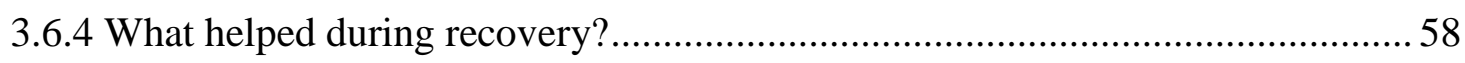

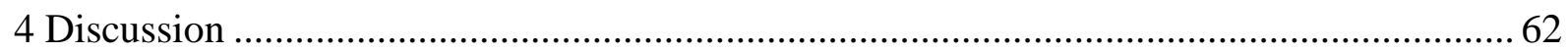

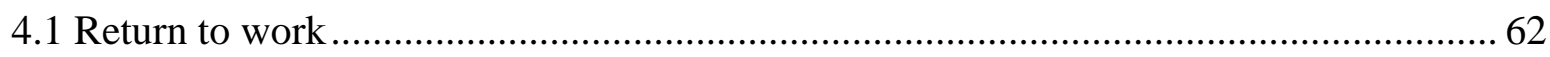

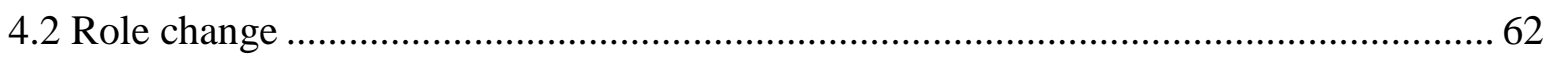

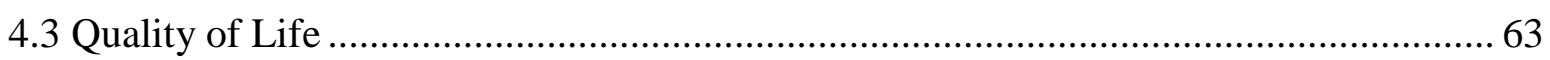

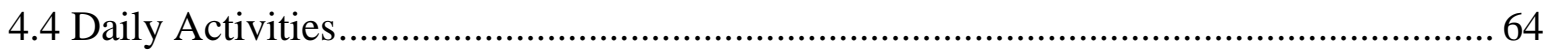

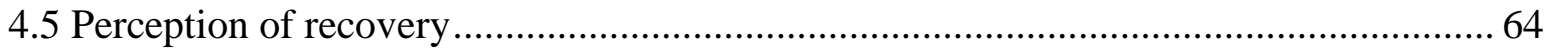

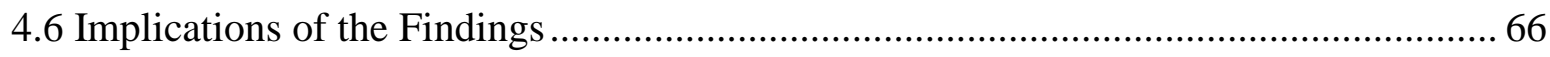

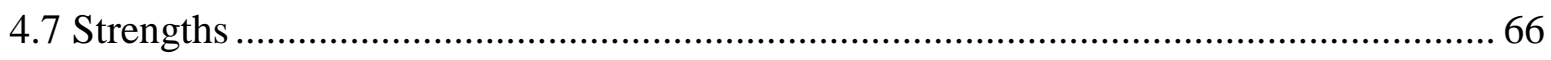

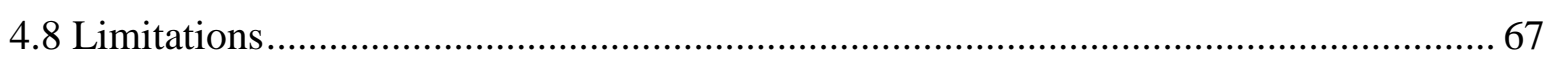

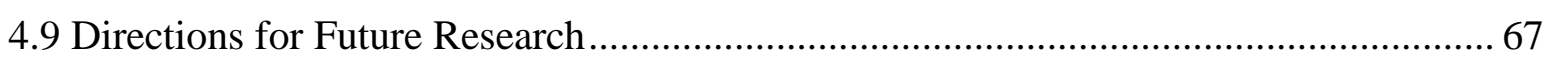

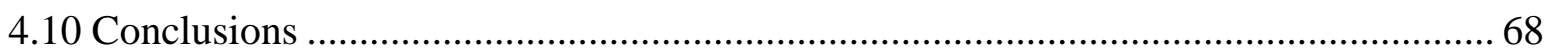

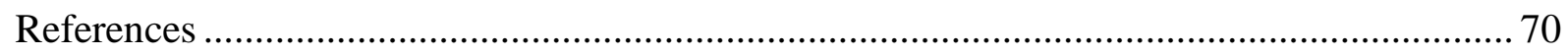

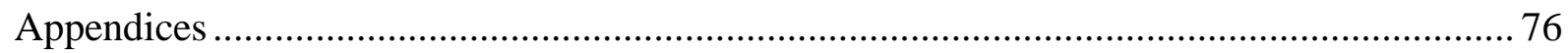

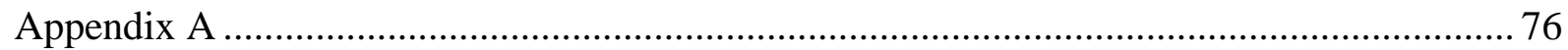




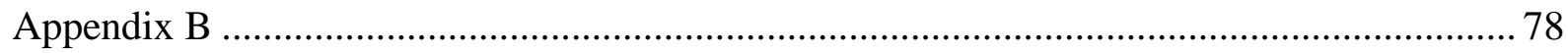

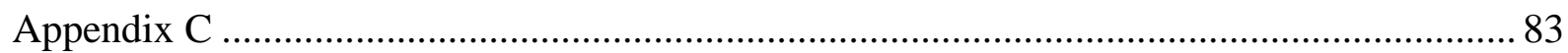

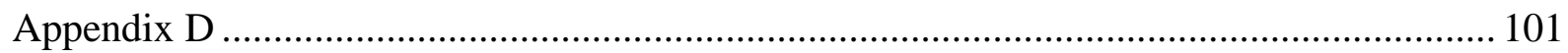

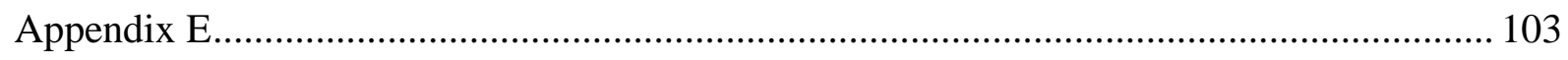

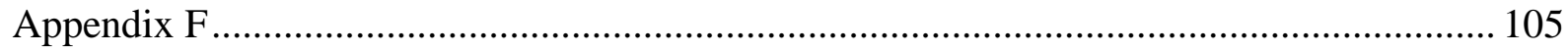

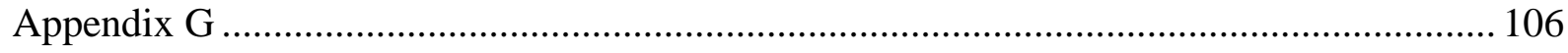

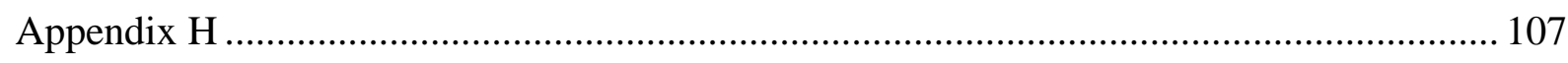

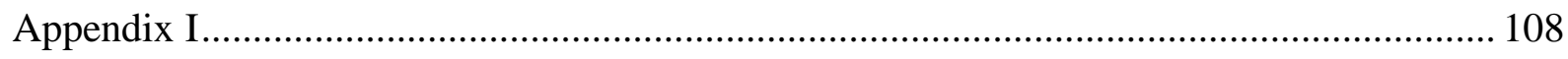




\section{Acknowledgments}

First and foremost I would like to thank my supervisor, Dr Audrey McKinlay, whose support in this enormous learning curve has been unwavering. Her wisdom, encouragement and approachability has been greatly appreciated and valued. Secondly, thank you to Professor Randolph Grace, whose knowledge and advice has been invaluable.

A big thank you to Richard, who has always believed in my abilities, and has inspired and motivated me throughout the process. Thank you to my parents, for always supporting me and encouraging me to be the best I can be, and to my friends and family who have provided me with all the laughs and love I've needed in both the hard times and the good times.

Last but certainly not least, thank you to the participants, for their willingness to share their personal experiences with me. I have been amazed by their stories of perseverance and resilience. This thesis would not have been possible without their valuable input, and I am truly grateful for their participation. 


\section{List of Tables}

Table 1

Demographics 26

Table 2 Role Change Patterns After Injury According to Individual Roles.

Table 3 WHOQOL-100 Domain Scores After Injury According to Injury Type 30

Table 4 Correlations of WHOQOL-100 Domain Scores with Covariates After Injury 33

Table $5 \quad$ Summary of Hierarchical Regression Analyses for Injury Type predicting QOL After Injury Whilst Controlling for Other Variables. 37

Table 6 Scores of Satisfaction with Ability to do Daily Activities After Injury According to Injury Type. 42

Table 7 Emergent Codes and Themes From Qualitative Data .45 
CHANGE IN LIFE ROLES IN OLDER ADULTS AFTER TBI

\section{List of Figures}

Figure 1 Mean Role Change Patterns After Injury According to Injury Type 28

Figure 2 Mean WHOQOL-100 Domain Scores After Injury According to Injury Type ..... 32 
CHANGE IN LIFE ROLES IN OLDER ADULTS AFTER TBI

\section{Abbreviations}

ACC Accident Compensation Corporation

GCS Glasgow Coma Scale

LOC Loss of Consciousness

PTA Post Traumatic Amnesia

mTBI Mild Traumatic Brain Injury

QOL Quality of Life

TBI Traumatic Brain Injury

WHOQOL-100 World Health Organisation Quality of Life Questionnaire 


\begin{abstract}
Traumatic Brain Injury (TBI) is a major health problem for adults aged 50-65. Due to New Zealand's aging population, it is important that consideration is given to outcomes after mild TBI (mTBI) in older adults, as these have implications for both the workforce and for the individual's quality of life (QOL). This study examined changes in life roles, QOL, satisfaction with ability to perform daily activities and the perception of support available and the rehabilitative experienced in older adults who had experienced mTBI $(n=15)$, and compared them to older adults who has experienced an orthopaedic injury $(n=15)$.

Participants completed two quantitative measures; The World Health Organisation Quality of Life Questionnaire -100 Version and The Role Checklist, and also completed a semistructured phone interview to elicit both quantitative and qualitative data. Results demonstrated that older adults with mTBI experienced more role losses (and had most losses in the worker role), had lower QOL, and were less satisfied with their ability to perform daily activities than older adults with orthopaedic injuries. Additionally, participants with TBI were more likely to perceive the support available to them during their recovery in a negative way, and were more likely to experience barriers to accessing support than adults with orthopaedic injury. These results demonstrate the detrimental impact mTBI can have on an older adults life roles and QOL, and highlights the need for services that adequately support older adults with mTBI to regain as much of their pre-injury functioning as possible, so they can return to their pre-injury life roles and maintain a good QOL.
\end{abstract}




\section{Introduction}

\subsection{Overview}

Traumatic brain injury is a major health problem for older adults as a result of falls ${ }^{1}$ (Thompson, McCormick, \& Kagan, 2006). Traumatic brain injury(TBI) outcomes are an important economic and health issue, as New Zealand has an aging population; within 25 years it is expected that the older population will have doubled (Statistics New Zealand, 2009). Consequently, older people make up a significant proportion of New Zealand's workforce, for example, in 2011 approximately 1 in 3 people engaged in the New Zealand workforce were aged over 50, and 1 in 10 were over 60 (McPherson, 2015). Because of our aging population and increasing life expectancy (Statistics New Zealand, 2009), there is the potential for New Zealand to follow many of its peer countries in raising the retirement age (O'Connell, 2014), and older adults will be expected to maintain employment for longer than previous generations. However, consideration needs to be given to how factors such as TBI may impact on an individual's ability to fulfil expectations of delayed retirement or engagement in other life roles, particularly as older adults experience disproportionally worse outcomes after mTBI than younger adults(Dijkers, Brandstater, Horn, Ryser, \& Barrett, 2013). Identifying barriers to work and community engagement is important as the ability of older adults to return to the workforce or other life roles following injury has both economic implications, and perhaps more importantly also contributes to a sense of well-being for that person.

\footnotetext{
${ }^{1}$ No consensus regarding the definition of older adulthood currently exists, therefore 50 years+ will be used in this thesis
} 


\subsection{Epidemiology of TBI}

Traumatic brain injury severe enough to result in hospitalisation has been estimated to affect 10 million people worldwide annually (Langlois, Rutland-Brown, \& Wald, 2006b). Exact incidence rates are often difficult to establish due to substantial differences in reporting methods (Bruns \& Hauser, 2003), as well as under-reporting of injuries, such as those who sustain a TBI but fail to seek care (Langlois et al., 2006b), or those who fail to recall a previous injury. Consequently, it is likely that the true impact of TBI is underestimated by the official statistics.

Some individuals are considered to be more at risk of experiencing a TBI event than others. For example, it is well documented that males are twice as likely to experience TBI (Langlois, Rutland-Brown, \& Thomas, 2006a). Certain age groups are also more likely to sustain TBI, with population studies demonstrating higher incidence of TBI in early childhood, late adolescence and in individuals over 60 years of age (Bruns \& Hauser, 2003).

The leading causes of TBI include transport related causes, falls, sports and recreation, and assaults, with mechanism of injury often being related to the individual's demographics (Bruns \& Hauser, 2003; Langlois et al., 2006b). Amongst males and those of ethnic minorities, young adults are more likely to sustain an injury through violent acts and motor vehicle accidents, whereas children and the elderly are more likely to sustain injuries through falls (Bruns \& Hauser, 2003).

1.2.1 TBI in New Zealand. Barker-Collo, Wilde, and Feigin (2009) used a national database to estimate TBI incidence in New Zealand by TBI-related hospital discharges, finding that the age-standardized hospital based incidence rate in 2003/2004 was 342 per 100,000. However, Feigin et al. (2012) estimated incidence of TBI from a rural and urban population base in 2010 and found incidence of mild TBI to be 749 per 100,000 and 
moderate-severe TBI to be 41 per 100,000 cases, making the overall estimated incidence 790 per 100,000 . It is likely that this figure is more accurate due to the large community population base used and is more likely to include the mild TBI that may have been missed when using a hospital-based sample. While only $10 \%$ of those with mTBI will have ongoing problems (Kibby \& Long, 1999), TBI is an important health issue within New Zealand because of the large number of people affected.

1.2.2 TBI in older adults. There is increasing evidence that as an individual progresses to older adulthood, the likelihood of sustaining a TBI increases. For example, those aged 65 and over have been demonstrated to be at higher risk because of the increased likelihood of falls in older adulthood (Bruns \& Hauser, 2003). Further, research suggests that the ageadjusted hospitalization rate for TBI more than doubles for those aged 65 and over (Coronado, Thomas, Sattin, \& Johnson, 2005). Similarly, in research that examined TBI incidence rates across all adulthood, $44 \%$ of those included were aged over 50 (Stocchetti, Paternò, Citerio, Beretta, \& Colombo, 2012). Conversely, it is generally accepted that TBI incidence actually decreases in middle-aged adults (approximately aged 30-65) (Bruns \& Hauser, 2003). However the broad scope of this age range and the lack of research looking specifically at the older ages within this range makes it difficult to draw concrete conclusions on the effects of age on TBI incidence in those aged 50-65 years still in employment..

1.2.3 Traumatic Brain Injury classification. TBI can be classified into mild, moderate and severe categories (McCrea et al., 2009) using a number of indicators such as duration of loss of consciousness (LOC), length of post traumatic amnesia (PTA) and the Glasgow Coma Scale (GSC)(McCrea, 2008). The GSC is a 15 point scale that scores an individual on aspects such as level of consciousness and their eye, motor and verbal reactions, with 3 being the lowest obtainable score indicating coma, and 15 being the highest score, indicating normal responses(Teasdale \& Jennett, 1974). A TBI is generally considered severe if there is a LOC 
for $>$ than 36 hours, PTA $>36$ hours and a GCS score $<9$. A moderate TBI is usually classified as LOC $>20$ minutes, PTA $>24$ hours, lowest GSC score is $<13$ but $>8$ and/or if haematoma, penetrating TBI, or brain stem injury are present. TBI is classified as mild if LOC $<20$ minutes, PTA $>24$ hours and lowest GCS $>12$ with no abnormalities on imaging (McCrea et al., 2009). The exact severity of TBI is can be difficult to diagnose due to differing classification methods, however, most research suggests that $80 \%$ of injuries will be mild, 10\% moderate and 10\% severe (Bruns \& Hauser, 2003).

\subsection{Outcomes of TBI.}

The consequences of TBI can range from subtle deficits that resolve within one or two months in the case of mild TBI (Konrad et al., 2011) to severe cognitive, physical, behavioural and emotional consequences that can be life-long struggles (Langlois et al., 2006b). In extreme cases, TBI can result in persistent coma or death. The level of disability can affect an individual's ability to perform daily activities and return to work, as well as put them at risk of developing other physical and mental health issues (Langlois et al., 2006b). Further, contrary to the expectation that all mild TBI symptoms will resolve within a matter of months, outcomes may differ depending on the age of the individual. Some older adults and younger children may report ongoing symptoms for mild TBI past 12 months and have more severe outcomes (McCrea et al., 2009)

\subsubsection{Outcomes in older adults. Research suggests that older adults (50+) do not} recover as quickly or as fully from TBI when compared to younger adults. For example, older adults have reported experiencing increased dependence on others, more medical complications from their injury, and require increased rehabilitative input in order to return to pre-injury functioning (Thompson et al., 2006). Older individuals have also been reported as having higher mortality rates following TBI when compared to younger adults (Thompson et al., 2006). Increased adverse outcomes could, in part, be due to normal aging processes. 
However, it is also possible that the negative effects of TBI are exacerbated due to the inappropriate management of the associated injury symptoms. For example, Dijkers et al. (2013) demonstrated that younger individuals received more rehabilitative input than older individuals as their length of stay in a rehabilitative facility was shorter and they received less hours of rehabilitation on a daily basis than their younger counterparts. Dijkers et al. (2013) considered whether this was due to a lack of interest or tolerance to therapies from older adults or perhaps a form of discrimination against age in that older adults will have less time to properly utilize skills taught to them as they are already retired, or have been contemplating retirement before their injury, and are unlikely to remain working for much longer. Accordingly, a TBI event has the potential to have a catastrophic effect on older adults and their everyday functioning, impacting on their ability to perform existing roles and responsibilities, which in turn could affect their emotional well being and perceived quality of life (QOL).

1.3.2. Outcomes according to severity in older adults. Research with older adults has consistently reported that mild TBI (mTBI) has a disproportionately worse effect on outcomes for older adults compared to younger adults. For example, Dijkers et al. (2013) reported that for elderly patients (aged 65 and over) functional outcome was worse than for the younger comparison groups (aged 15-65), despite their overall injuries and TBI being generally less severe. Additionally, older patients who had mTBI were significantly less likely to survive. Thompson et al. (2006)suggested this could be because normal aging processes exacerbate the damage in the brain caused by the injury, and that older adults are more likely to be regularly using anti-coagulants such as aspirin, which can increase the risk of bleeding in the brain. Similarly, Dijkers et al. (2013) reported that although individual's over 65 years of age generally had milder TBI, they still regained less functionally ability and cognitive improvements after their in-patient rehabilitation. Patients over 65 also had a 
shorter length of stay in rehabilitation and received fewer hours of therapy overall. Further, Testa, Malec, Moessner, and Brown (2005) examined the differences in outcomes between younger and older adults after TBI and reported that severity only weakly predicted independent living, employment and level of functioning 1 to 2 years post injury, and Yi and Dams-O'Connor (2013) Yi and Dams-O'Connor (2013) found that injury severity was not a strong predictor of psychosocial outcomes for older adults. Rothweiler, Temkin, and Dikmen (1998) reported that individuals aged 60 and over with mild uncomplicated TBI were more likely to be rated as moderately disabled 1 year post-injury $(57 \%)$ than those who were aged 50 and under with mild uncomplicated TBI (under 14\%). The authors suggested that the severity of TBI may be underestimated in older adults as a result of complicating factors, such as a higher incidence of medical complications (e.g. heart attack), a higher rate of comorbid medical conditions and a higher incidence of subdural bleeds, which may contribute to a more severe injury than originally suggested. Because outcomes for older adults are qualitatively different regardless of severity, it is important that this group be evaluated separately from younger adults in order to accurately identify difficulties that they might have in resuming pre-injury roles including work, and engagement with family and community.

\subsection{Effect of TBI on return to work}

1.4.1 Effect of TBI on return to work for all age groups. For many people, return to work is an important component of recovery from TBI because it contributes to the individuals sense of social and psychological well-being and QOL, as well as having an economic benefit for the individual and for the community (Shames, Treger, Ring, \& Giaquinto, 2007). A review by Shames et al. (2007)which examined return to work following TBI, reported that the rate of return to work varied greatly between studies, ranging from $12.5 \%-70 \%$ (Watanabe, Miller, \& McElligott, 2003), The authors discussed the difficulties in defining return to work, for example, whether return to work means completely resuming 
pre-injury employment, or whether if the individual starts another job with reduced hours that is also classified as successful return to work. Nevertheless, Shames et al. (2007) described successful return to work being influenced by a number of factors, including severity of injury, pre-injury employment status, educational background as well as other psychosocial, economic and cultural factors.

1.4.2 Effect of Age on return to work. Studies specifically comparing older and younger adult groups have demonstrated the older adults are less likely to return to work after TBI. For example, Ponsford, Olver, Curran, and $\mathrm{Ng}$ (1995) provided evidence that age has a more negative impact on return to work in older adults than in younger adults with mild to severe TBI. Results demonstrated that employment 2 years post TBI can be predicted by a combination of variables that included total score on the Disability Rating Scale (a functional assessment measure for TBI)(Rappaport, Hall, Hopkins, Belleza, \& Cope, 1982), total score on the GCS and age (specifically if they were under or over 40 years at time of injury). This combination of variables was identified in a discriminant analysis which correctly classified approximately $70 \%$ of grouped cases, which was cross validated with another sample. Similarly, Keyser-Marcus et al. (2002) investigated the relationship between patient characteristics and return to employment in adults aged 18-55 at 1 to 5 years post TBI and provided additional evidence that individuals aged over 40 were less likely to be employed at 1 to 5 years follow up than their younger counterparts. Older age was found to be the most significant predictor for not returning to work up to 4 years post-injury, demonstrating that effects of TBI on return to employment are evident both immediately after injury as well as having a detrimental impact in the long-term (Keyser-Marcus et al., 2002). A review that looked at community integration after TBI in older adults (Ritchie, Wright-St Clair, Keogh, \& Gray, 2014) reported that older adults were more likely to be unemployed after TBI or to retire because of it. Testa et al. (2005) compared individuals aged 18 -85 with mild to severe 
TBI to those with an orthopaedic injuries. The authors found that older adults with TBI were more likely to have a changed employment status than both their younger counterparts and all orthopaedic injury participants, suggesting that the neurological impact of TBI was a factor that contributed to failure to return to work in older adults, more than a traumatic event alone. Not only is it important to consider the economic impact of older adults being unemployed, but to also note that those employed will have an improved QOL (Andelic et al., 2009), and that employment is important to an individuals' overall sense of wellbeing and role participation (Ritchie et al., 2014).

\subsection{Changes in Life Roles}

TBI affects not only on the ability to return to employment, but also on an individual's role participation. A role may be defined as the expected pattern of behaviour associated with occupancy of a distinctive position in society (Heard, 1977). These roles encompass occupational, vocational family and social domains, allowing a person to establish their identity and meet their needs through these roles (Hallett, Zasler, Maurer, \& Cash, 1994). Consequently, fulfilment of these roles plays an instrumental part in a person's perceived QOL and their ability to contribute to the wider community. For example, older adults often provide care for their own aging parents, grandchildren and volunteering/assisting with the needs of other family or non-family. Consequently, it is essential that older adults are supported in maintaining as many of their life roles as possible as they age not only for their own well-being but also for the benefit of others and the wider community.

Research looking specifically at role change amongst older adults after TBI is limited. A single qualitative study (Layman, Dijkers, \& Ashman, 2005) has explored the impact of TBI on role change in 8 couples aged 50 and over, where one of the couple had sustained a mild to severe TBI. Their experiences were compared with those of older couples who had 
endured another crisis event. For the purposes of the study, role change was defined as “changes in participation in partnership activities" (Layman, Dijkers, \& Ashman, 2005), which included financial management, decision-making and household tasks. Layman et al. (2005) found that half the individuals with TBI indicated that their participation in these roles had reduced following their TBI, while two said that some roles had changed and others had not, and two said that their role participation had not changed. In the non-TBI comparison group, only three partners reported that they had taken on more responsibility, suggesting that reduced role participation in those who experienced the non-TBI crisis event was less frequent than in those who had sustained a TBI. The authors commented on the difficulty of determining whether changes were age-related or as a result of the TBI, and noted the overlapping symptoms. They also discussed the similarities in changes in role participation between the TBI and comparison group, and considered this as further evidence that agerelated changes are indistinguishable from the effects of TBI in this age-bracket. Whilst this study provides some insight into role change in older adults, the small sample size makes it difficult to generalize these finding to the general older adult population. The authors highlighted the need for further research to differentiate the effects of TBI and aging on older adults.

There is a greater abundance of non age specific research aimed at evaluating role changes following TBI. For example,Hallett et al. (1994) documented the significant role change that occurs in adults who experienced severe TBI. Of their 28 participants, they determined that every participant had some degree of role change after their injury, and that $71 \%$ of these changes were role losses. Sixty-four percent of participants reported three or four role losses, whilst $94 \%$ of participants reported only one or no role gains. The worker role was the role that had the most loss reported $(85 \%)$, with the majority of participants reporting that the lost role was very valuable to them, and the feelings associated with this 
loss included worthlessness and anger. This is in agreement with previous studies suggesting that returning to work is after TBI is difficult (Andelic et al., 2009; Shames et al., 2007), and often has a negative impact on individual wellbeing.

Similarly, Sloan, Winkler, and Anson (2007) examined role participation and community integration in 13 adults who had sustained a severe TBI and were approximately 9 years post injury. The average age of the participants at the time of injury was 26 years old. They found that community integration amongst their participants was low, and that those who suffered from a greater level of disability participated in fewer community and social roles. The authors reported that those who generally scored high on functional independence had a higher number of life roles. However, those who had high functional independence, but a lower number of life roles reported low life satisfaction, suggesting that participation in life roles is more important than functional independence when it comes to perceived satisfaction with life. Whilst these findings provide an interesting insight into the workings of role participation in overall life satisfaction, they are generally focused on those with severe TBI. More research is needed to see if increased number of role losses are also found among older adults who have sustained mild TBI.

\subsection{Quality of life after TBI}

QOL is difficult to define due to its all-encompassing nature. However the World Health Organisation defines QOL as "individuals perception of their position in life in the context of their culture and value systems in which they live and in relation to their goals, expectations, standards and concerns"("WHOQOL: Measuring Quality of Life," 2016). This can include an individual's satisfaction with their psychological state, physical health, level of independence, social relationships and personal beliefs ("WHOQOL: Measuring Quality of Life," 2016). QOL after injury is often also discussed as health-related QOL, referring to the 
impact a medical condition may have on specific domains. Interpreting outcomes looking into QOL can be difficult due to differing measures used across studies, and similarly, the vast range of cultural and individual aspirations, values and expectations makes finding a universally appropriate tool difficult (Rose \& Johnson, 1996).

Research into the QOL of older adults after TBI is limited, with most research focusing on QOL in younger populations. However these studies can provide insight into the impact of TBI on QOL in other populations, and can suggest hypotheses about the impact on older adults. Evidence suggests that there is a relationship between older age and poorer outcomes after any traumatic injury, such as a decline in functional status post-injury, decreased QOL, changes in living arrangements and decreased independence (Jacoby, Ackerson, \& Richmond, 2006). This trend persists even after other variables such as injury severity, number of injuries and complications are controlled for. When compared with younger adults after traumatic injury, older adults were much more likely to need further care and were less likely to return home than their younger counterparts (Jacoby et al., 2006).

In a review of research approaches and findings of QOL after TBI in adults of all ages with injuries of all severities, Dijkers (2004) suggested that generally individuals reported lower QOL than comparison groups when QOL was defined in terms of achievements, for example being able to partake in satisfying work or having close friends. Further, when QOL was measured in terms of subjective well-being (e.g. "weighing what one has or is against ones standards and expectations") those with TBI tended to report lower life satisfaction than those without. However, variable sample sizes made these findings difficult to generalise, and many individuals with TBI reported similar or higher satisfaction with life when compared to those without TBI (Dijkers, 2004). Whilst previous research has been varied, there is 
evidence to suggest there is a link between TBI and QOL, and therefore further investigation is needed to clarify this relationship.

1.6.1 Quality of life and aging after TBI. In a study that examined trajectories of life satisfaction in the first 5 years following TBI in adults of all ages (mean age 38) with all levels of injury severity, Resch et al. (2009)concluded that although older age was a significant predictor of greater life satisfaction at first assessment, there was no difference between age groups at subsequent follow ups, and therefore the authors concluded that age did not predict life satisfaction over time after TBI.

Other factors that may contribute to an older persons subjective well-being include social contact, having an income and belief in their competence both in maintaining independent living and in the productive skills they possess (Pinquart \& Sörensen, 2000).Consequently, it is important that older adults are supported to maintain their independence and to continue engagement in the workforce and wider community, for both the individual's well-being and for the benefit they provide to the community.

\subsection{Rehabilitation}

Rehabilitation aims to help the individual achieve a return to previous levels of functioning as completely as possible. This involves working not only on their physical limitations but also their emotional, social and community function in order to maximise QOL for that person (Chua, Ng, Yap, \& Bok, 2007). Individual's living in New Zealand experiencing an injury such as TBI, are entitled to support from the Accident Compensation Corporation ("Introduction to ACC," 2015). ACC is a crown entity that is responsible for providing no-fault personal injury insurance to all living in and visiting New Zealand. In their role ACC aims to ensure individuals get treatment for their injury and help people get back to their pre injury life as soon as possible. This can include coordinating and overseeing the 
support the client receives, providing weekly compensation, and assisting in payment for medical treatment costs ("Introduction to ACC," 2015). ACC provides a concussion service that aims to "provide early intervention rehabilitation to support client recovery and prompt return to everyday life, including work or school"("Concussion service," 2015).

Rehabilitation after TBI can be complex due to the far reaching impacts of TBI as previously outlined. Consequently, effective rehabilitation often requires a team approach (Glenn, 2012). However, interpreting evidence for the effectiveness of rehabilitation after TBI can be difficult due to the differing nature of injuries and subsequent recovery (Chua et al., 2007). In a comprehensive review Turner-Stokes, Disler, Nair, and Wade (2005) found strong evidence to suggest that the majority of individuals with mild injuries will make a good recovery, and that those with moderate-severe injuries will benefit from a more intensive rehabilitation, and demonstrated earlier and more rapid functional gains and a shorter length of stay than those who did not receive such rehabilitation.

1.7.2 Outcomes after rehabilitation in older adults. Cifu et al. (1996) examined functional outcomes in older adults with TBI compared to younger individuals with TBI and found that despite older adults averaging a significantly longer length of rehabilitation stay and therefore higher rehabilitation costs, there was a lower rate of functional improvements compared to the younger group. Research has demonstrated that not only do older people experience more negative effects from mild TBI than younger people, but in some cases less time is spent rehabilitating older adults (Dijkers et al., 2013). It has been suggested that older individuals may be subject to ageism (i.e. discrimination against someone on the basis of their age). Ageism could explain why older adults received less rehabilitative input than their younger counterparts (Dijkers et al., 2013). 
1.7.3 Perceptions of rehabilitative services available. Another facet to rehabilitation after TBI is how the individual perceives the rehabilitative input they receive. There have been a number of qualitative studies that have aimed to quantify individuals' rehabilitative journey after TBI, and have demonstrated the impact that a good or bad experience can have. For example, Sample and Darragh (1998) documented issues around barriers to accessing support after TBI. They interviewed 21 adult women living in both rural and urban areas in Colorado, and found that all of these women had experienced barriers to accessing care, which included problems with service providers, financial challenges, a lack of information and services available and a lack of care co-ordination. Similarly, Darragh, Sample, and Krieger (2001) demonstrated the importance of having a medical practitioner who demonstrated empathy and put the client as the centre focus in therapy. Participants often described the role of the therapist like a friend or mentor, and interestingly, the individuals experience of the practitioner on a personal level influenced the individuals' perception of the treatment efficacy, rather than the skills and expertise that practitioner held (Darragh et al., 2001). Participants also noted that when they did not feel like they valued the personal relationship with them and the practitioner, they became easily frustrated with their services (Darragh et al., 2001).

There is little research specific to older adult populations looking at perceptions of the rehabilitative experience, and whilst we can generalise from previous findings on general adult populations, one of the aims of this study is to examine specifically older adults experience of support they receive after TBI.

\subsection{Research Aims and Hypotheses}

The current study aims to expand on previous research by examining return to work after TBI in older adults, their perceived QOL and whether QOL is impacted by role change, 
and satisfaction with ability to participate in daily activities in older adults after TBI. It also aims to describe and examine individual's experience of support and recovery after TBI. This study will compare older adults with TBI to older adults with orthopaedic injury, to distinguish whether changes are a result of a traumatic injury event in older adulthood, or because of ongoing TBI symptoms. This study will take into account the effect that current age, age at time of injury, time since injury and sex may have on these outcomes.

The study aims and hypotheses are as follows:

1. To investigate the effect of TBI versus Orthopaedic injury on return to work and other role change patterns. This study will measure role change patterns with The Role Checklist (Oakley, Kielhofner, Barris, \& Reichler, 1986).

It is hypothesized that older adults with TBI will be less likely to return to work and will experience a greater amount of role change than older adults with orthopaedic injury.

2. To investigate the effect of injury type on perceived QOL in older adults. This study will measure QOL using the World Health Organisation Quality of Life Questionnaire (WHOQOL-100), which examines the QOL domains of physical, psychological, independence, social relationships, environment and spiritual.

It is hypothesized that older adults with TBI will score significantly lower on WHOQOL-100 domains than older adults with orthopaedic injury, specifically on physical, psychological, independence and social relationship domains.

3. To investigate the effect of injury type on individuals satisfaction with their ability to perform daily activities. This study uses a likert scale self-report of ability satisfaction 
for each activity based on The Lawton Instrumental Activities of Daily Living Scale (Lawton \& Brody, 1988).

It is hypothesized that older adults with TBI will report less satisfaction with their ability to perform activities of daily living than older adults with orthopaedic injury.

4. To investigate and describe the recovery and support available in New Zealand for older adults after injury, comparing the differences between perceived support and experience of recovery in older adults with TBI and older adults with orthopaedic injury. This information will be gathered through a semi-structured interview and will be qualitative data.

It is hypothesized that older adults with TBI will be more likely to perceive a negative experience of their recovery and support available following injury when compared with older adults with orthopaedic injury. 


\section{Method}

\subsection{Participants}

A total of 30 individuals were recruited; TBI $(n=15)$, and those with orthopaedic injury $(n=15)$ to act as controls. An orthopaedic injury group was chosen to control for the effects of trauma, pain and disruption to daily routine that would be experienced by a TBI group. Whilst this may be considered a small sample size for quantitative data, this sample size was chosen as it achieved saturation for the qualitative component of the study (Mason, 2010), and in this case did achieve sufficient power when testing the quantitative measures. Injury participants were recruited through the community, which included placing advertisements on suitable notice boards such as doctors' surgeries, rehabilitation facilities and physiotherapists (Appendix A). Word of mouth and social media was also utilized. Organisations such as the Brain Injury Association and Age Concern were also contacted directly. The criteria for inclusion in the TBI group included: a) at least 6 months post injury, b) injured between 5065 years of age and still within that age bracket, c) a diagnosis of mTBI or concussion. Orthopaedic participants were required to meet the same age criteria and time post injury as the TBI group but were not included if they reported a previous or present traumatic brain injury. Their bone break must have resulted in serious disruption to their daily life i.e. surgery, a hospital stay or time off work. One participant in the TBI group and two participants in the orthopaedic group were unable to be contacted for their semi-structured interview but did complete self-report questionnaires.

2.1.1 Classification of TBI. TBI Participants were asked if they were given a severity classification at the time of their injury by a medical professional. If not, then classification was base on GCS score if it was known, LOC and PTA.

\subsection{Design}

The present study employs a cross-sectional research design. 


\subsection{Measures}

2.3.1 Life role change. Role change was measured by the Role Checklist (Oakley et al., 1986), which had been adapted to be presented in a more accessible and clear way (e.g. picture depictions of each role) (Bogues \& Wilson, n.d.), which was more suitable for a older population with TBI. The role checklist elicits information about a person's occupational roles, including both productive and leisure roles. Roles included are student, worker, volunteer, looking after someone, looking after my home, doing things with my friend(s), doing things with my family, doing things with my church/mosque/synagogue etc, having a hobby/hobbies, doing things with wider groups, and there is also opportunity for the participant to add any roles not mentioned. Using a visual scale (see appendix B), participants were asked to indicate whether they did this role in the past (yes $=1$, no $=0$ ), they were currently doing this role (yes $=1$, no $=0$ ), or they would like to do this role in the future (yes $=1$, no $=0$ ) A maximum score of 10 for past roles indicated participation in all roles before their injury, a maximum score of 10 for present roles indicated that they currently participated in all roles and a maximum score of 10 for future roles indicated they would like to participate in all roles in the future. Conversely, a minimum score of 0 for past, present or future indicates they participated in no roles before their injury, no roles currently and would like to participate in no roles in the future. For the purposes of this study, participants were asked to indicate whether they performed the role before their injury instead of in the past in general. The Role Checklist also asked participants to indicate for each role how valuable this role is to them (not important, quite important or very important). 
2.3.2 Quality of life. QOL was measured by the World Health Organisation Quality of Life Questionnaire (WHOQOL-100) (The WHOQOL Group, 1998), which consists of 100 questions rated on a 5-point Likert scale about perceived QOL over different domains (see appendix C). Domains include physical health, psychological health, level of independence, social relationships, environment, and spirituality/religion/personal beliefs. There are 24 individual facet scores within the 6 domains, for example, the physical pain domain includes the facets of pain and discomfort and vitality and fatigue. Items were scored 1-5, with possible 4-20 points available for each. Lower scores indicate lower QOL and higher scores indicate higher QOL. The WHOQOL-100 also elicited demographic information.

2.3.3 Semi structured interview. A semi-structured interview was conducted with each participant over the phone in order to elicit more qualitative information regarding the effects of the injury and subsequent recovery. Participants were asked about the sequence of events immediately after their injury and the support they received during their recovery process to get a feel for their experience of the acute and long-term support they received. Questions asked during the interview can be found in Appendix D.

2.3.4 Information about injury. During the interview, questions were asked regarding the injury, to gain information regarding the mechanism of injury, severity of injury, age at the time of injury and current age.

2.3.5 Satisfaction with life roles. A measure of satisfaction with ability to perform current and past life roles was elicited during the semi structured interview. Participants were first asked to score their satisfaction with their ability to perform the roles they indicated they performed in the past on 1-5 Likert Scale, and then asked to score their satisfaction with the roles the indicated they perform currently on the same scale. This score was used as a talking 
point as to elicit more information around the reasoning behind their satisfaction, and to create discussion around what impedes on and improves their satisfaction.

2.3.6 Daily activities. Participants were also asked about their satisfaction with their ability to perform instrumental daily activities currently, and rated their satisfaction on a 1-5 Likert Scale. The activities discussed were taken from The Lawton Instrumental Activities of Daily Living Scale (Lawton \& Brody, 1988). Participants were prompted regarding the reasoning behind their answer to elicit more information about where their limitations lie and what struggles they encountered on a daily basis.

\subsection{Procedure}

When participants contacted the interviewer either through phone or email, the interviewer assessed their suitability for the study by gaining information about their injury, age and severity of injury in both groups. Participants were given a brief overview of the study, and where possible were sent a copy of the information sheet (appendix E) before agreeing to the study. The questionnaires were sent out by post to both groups of participants as they were recruited. Included in the questionnaire package was an instruction sheet (appendix F), an information sheet, a consent form (appendix G), a receipt of participant incentive form (appendix H), the WHOQOL-100, the Role Checklist and a \$10 either supermarket or fuel voucher depending on the participants preference. Also included in the questionnaire pack was an addressed pre-paid envelope for participants to return their questionnaires. Participants were given the contact details of the interviewer should they have any questions or difficulties with the questionnaires. Both questionnaires contained detailed instructions so participants could complete them without assistance.

2.4.1 Interview Procedure. After the questionnaire pack had been returned, the interviewer contacted the participant to make a convenient time for the semi-structured 
interview to take place. At this time participants were reminded of approximately how long the interview would take, and what the content of the interview would generally be about. The interviewer recorded participants' answers verbatim, and participants were informed that this was happening. If the interviewer was unclear about anything said, they clarified what they had recorded with the participant for accuracy. The participants completed Role Checklist was used as a guide for which roles to discuss. The 1-5 likert scale was explained and the interviewer checked the participants understanding of the scale before commencing the questions. At the end of the interview, participants were given an opportunity to ask any questions and thanked for their time.

\subsection{Ethical Approval}

The study was approved by the University of Canterbury Human Ethics Committee (see appendix I).

\subsection{Data Entry and Planned Statistical Analyses}

Data was analysed using SPSS Statistics 19 software. Descriptive statistics were performed using independent samples t-tests for continuous variables, chi-square test for categorical variables, and Fishers Exact test for categorical variables where cell frequencies were below 5 (Pallant, 2013).

To examine differences between TBI and orthopaedic participants in role change, Fishers exact tests were performed and a phi coefficient was produced to estimate the magnitude of effect. A phi of 0.1 or below indicated a small effect size, 0.3 indicated a moderate effect size and 0.5 and above indicated a large effect size (Cohen, 1992). To examine differences between total role loss, role gains and no role change, independent sample two tailed t-tests were performed and Cohen's d was used to estimate the magnitude 
of effects, with a Cohen's d of 0.2 and below indicating a small effect size, 0.5 indicating a moderate effect size and 0.8 and above indicating a large effect size (Cohen, 1992).

To examine differences between perceived QOL in older adults with TBI and orthopaedic injury, independent-sample t-tests were performed for each WHO-QOL domain score and Cohen's d was used to estimate the magnitude of effects. Hierarchical multiple regression was then performed for each domain that reached statistical significant in the ttests, in order to establish if injury type still predicted QOL after other predictor variables have been controlled for. This analysis also investigated the independent contributions of each predictor variable, and established which were the strongest predictors in each QOL domain.

To examine the differences between satisfaction with ability to perform daily activities in older adults with TBI and orthopaedic injury, independent sample two tailed t-tests were performed, and Cohen's d was used to estimate the magnitude of effect.

To analyse and quantify the information gathered in the semi-structured interviews, a thematic analysis method was used (Braun \& Clarke, 2006). A bottom-up approach was employed, in which interviews were first read and re-read, with initial ideas about what the data was saying noted. Secondly, a set of codes were developed by systematically reviewing all data, and coding interesting features of the data. Thirdly, codes were assessed for over arching themes, and codes and data were collated according to possible themes. Fourthly, themes were assessed to see if potential themes made sense with the overall data and with the codes created. Lastly, themes were refined and defined before writing the report of results (Braun \& Clarke, 2006). Codes were combined if they were seen to be representing the same meaning or information. Fishers exact tests were performed to establish statistically 
CHANGE IN LIFE ROLES IN OLDER ADULTS AFTER TBI

significant differences between theme endorsement between the two groups, and phi coefficients were produced to estimate the magnitude of difference. 


\section{Results}

\subsection{Demographics}

The demographic information for the sample is shown on Table 1. There were no significant differences between the TBI and orthopaedic group in terms of the number of males and females, age at the time of injury, or time since injury ( all ps>.30). However, there were significant differences in current age between $\mathrm{TBI}(\mathrm{M}=58.73, \mathrm{SD}=4.82)$ and orthopaedic groups $(\mathrm{M}=62.13, \mathrm{SD}=3.56 ; \mathrm{t}(28)=-2.20, p=.036, \mathrm{~d}=.802)$ with the orthopaedic group being significantly older. There was no statistically significant difference between TBI and orthopaedic groups in terms of educations or marital status ( $p>.30$ for both). Within the TBI group, the majority of participants sustained a mild injury (86.7\%) whilst 2 participants (13.3\%) sustained a moderate injury. 
Table 1

Demographics

\begin{tabular}{|c|c|c|c|c|}
\hline Variable & $\begin{array}{c}\text { TBI } \\
(n=15)\end{array}$ & $\begin{array}{l}\text { Orthopaedic } \\
\qquad(n=15)\end{array}$ & $t$ or $\chi^{2}$ & $p$ \\
\hline \multicolumn{5}{|l|}{$\operatorname{Sex} n(\%)$} \\
\hline Male & $8(53.3)$ & $5(33.3)$ & \multirow[b]{2}{*}{.543} & \multirow[b]{2}{*}{.461} \\
\hline Female & $7(46.7)$ & $10(66.7)$ & & \\
\hline \multicolumn{5}{|l|}{ Marital Status $n(\%)$} \\
\hline Single & $1(6.7)$ & $2(13.3)$ & \multirow{5}{*}{$3.56^{\mathrm{b}}$} & \multirow{4}{*}{.506} \\
\hline Married & $11(73.3)$ & $8(53.3)$ & & \\
\hline Living as married & $1(6.7)$ & $3(20)$ & & \\
\hline Separated & - & $1(6.7)$ & & \\
\hline Widowed & - & $1(6.7)$ & & \\
\hline
\end{tabular}

Education $n(\%)^{\mathrm{a}}$

Secondary School

$9(69.2)$

7 (46.7)

University

$1(6.7)$

$5(33.3)$

Postgraduate

$3(20)$

$3(20)$

Injury severity $n(\%)^{\mathrm{a}}$

Mild

Moderate

Mean age (range)

Mean age at injury (range)

Mean years since injury (range)
$13(86.7)$

$2(13.3)$
$62.1(57-67)$

$-2.198$

$-2.042$

$55.9(49-64) \quad 59.8(51-65)$

$2.9(0.75-9)$ $2.70^{\mathrm{b}}$ 


\subsection{Hypothesis One}

We predicted that older adults with TBI were less likely to return to work and would experience a greater amount of role change than older adults with orthopaedic injury. Table 2 presents the patterns of role change in each role by the TBI group and orthopaedic group. The greatest differences between groups were in the worker role, where in the TBI group $66 \%$ experienced role loss, $6.7 \%$ experienced role gain and $26.7 \%$ experienced no change in role, whereas in the orthopaedic group $6.7 \%$ experienced role loss, $6.7 \%$ experienced role gain and $86.7 \%$ had no role change, a difference that was statistically significant, and produced the largest effect size of all the roles $(\phi=.636, p=.001)$. Other roles that demonstrated statistically significant differences between TBI and orthopaedic groups included home maintainer $(\phi=.552, p=.006)$ and friend $(\phi=.552, p=.006)$, which both produced large effect sizes, and family member $(\phi=.482, p=.023)$, caregiver $(\phi=.447, p=.042)$ and religious participant $(\phi=.447, p=.042)$, which all produced a moderate effect size. For all of these roles, the TBI group experienced greater role losses than the orthopaedic group, whereas the orthopaedic group had a greater incidence of no role change than the TBI group. Within these roles, the TBI group had more role gains than the orthopaedic group in the roles of home maintainer, friend and family member, although these differences were small compared to role losses and no role change. Roles that did not show significant differences were volunteer $(\phi=.398, p=.080)$, hobbyist $(\phi=.397, p=.188)$, community participant $(\phi=.302, p=.215)$, which all did still produce a moderate effect size, and student $(\phi=.089$, $p=1.00)$. These results support hypothesis one that older adults with TBI experienced a significantly greater role loss in the worker role than older adults with orthopaedic injury, and also in the roles of home maintainer, friend, family member, caregiver and religious participant. 
Independent sample t-tests were conducted to compare total role losses, gains and no change between the TBI and orthopaedic groups. As seen in Figure 1, results demonstrated that the TBI group had significantly more role losses $(\mathrm{M}=3.47, \mathrm{SD}=2.80)$ than the orthopaedic group $(\mathrm{M}=.53, \mathrm{SD}=.834), \mathrm{t}(28)=3.89, p=.001$. A Cohen's $\mathrm{d}$ of 1.423 indicates a large effect size. The orthopaedic group reported a significantly higher incidence of no role change $(\mathrm{M}=9.33, \mathrm{SD}=1.18)$ than the TBI group $(\mathrm{M}=5.40, \mathrm{SD}=3.46), \mathrm{t}(28)=-$ 4.17, $p=<.001$. Again, the effect size $(\mathrm{d}=1.52)$ was large. The TBI group $(\mathrm{M}=1.13, \mathrm{SD}=$ 2.07) reported a slighter higher number of role gains than the orthopaedic group $(\mathrm{M}=.13, \mathrm{SD}$ $=.52)$, however this difference did not reach significance; $\mathrm{t}(28)=1.82, p=.080)$. These results support hypothesis one, as the TBI group demonstrated significantly more role losses than the orthopaedic group, and the orthopaedic group was more likely to have no role changes than the TBI group.

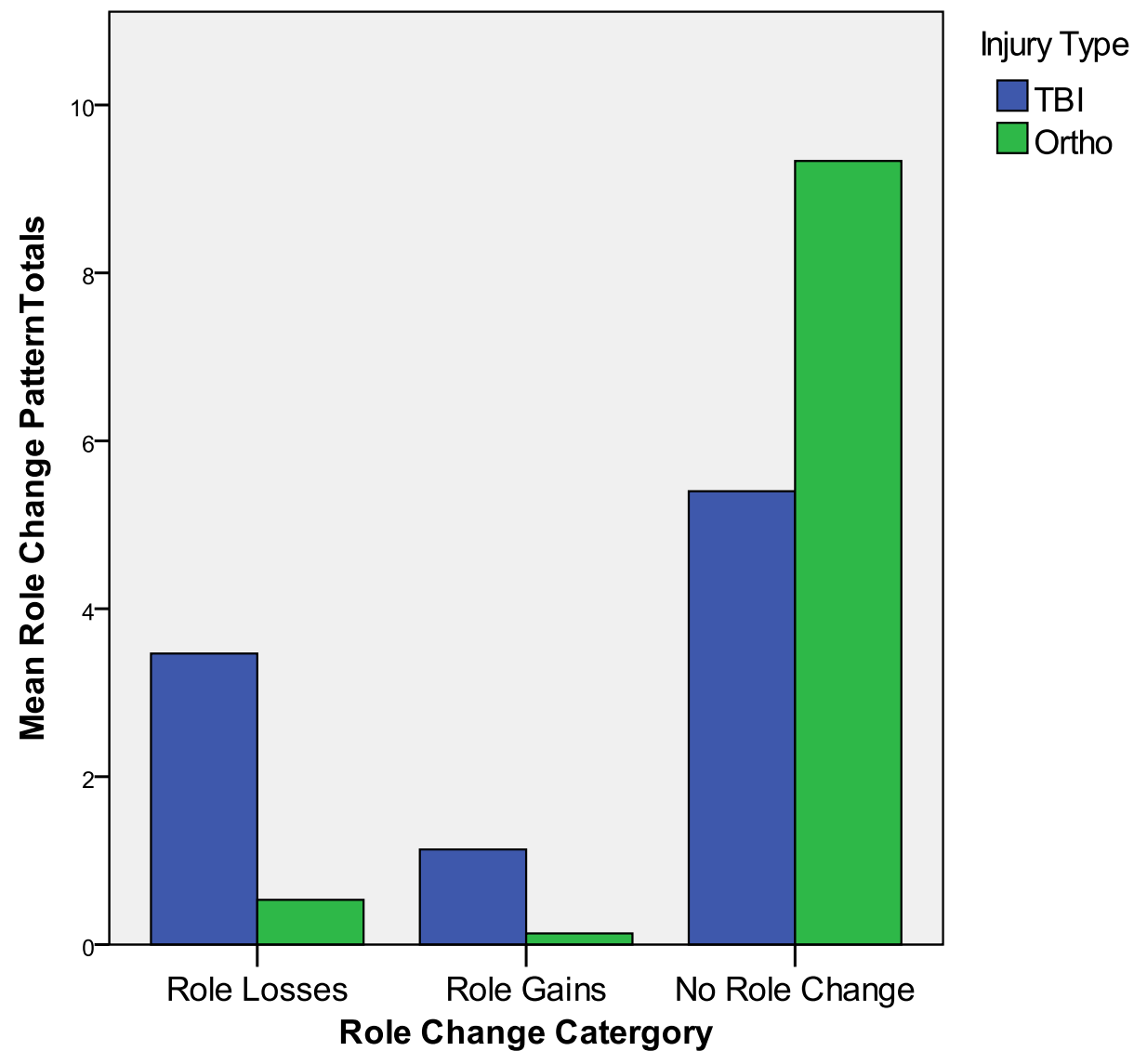

Figure 1. Mean Role Change Patterns After Injury According to Injury Type 
CHANGE IN LIFE ROLES IN OLDER ADULTS AFTER TBI

Table 2

Role Change Patterns After Injury According to Individual Roles

\begin{tabular}{|c|c|c|c|c|c|c|c|c|}
\hline Roles & \multicolumn{3}{|c|}{$\underline{\text { TBI }(n=15)}$} & \multicolumn{3}{|c|}{ Orthopaedic $(n=15)$} & $p$ & $\phi$ \\
\hline Student & $3(20)$ & - & $12(80)$ & $2(13.3)$ & - & $13(86.7)$ & 1.000 & .089 \\
\hline Worker & $10(66.7)$ & $1(6.7)$ & $4(26.7)$ & $1(6.7)$ & $1(6.7)$ & $13(86.7)$ & $.001 * *$ & .636 \\
\hline Caregiver & $5(33.3)$ & - & $10(66.7)$ & - & - & $15(100)$ & $.042 *$ & .447 \\
\hline Home Maintainer & $5(33.3)$ & $2(13.3)$ & $8(53.3)$ & - & - & $15(100)$ & $.006 * *$ & .552 \\
\hline Friend & $6(40)$ & $1(6.7)$ & $8(53.3)$ & - & - & $15(100)$ & $.006 * *$ & .552 \\
\hline Hobbyist & $2(13.3)$ & $4(26.7)$ & $9(60)$ & $2(13.3)$ & - & $13(86.7)$ & .188 & .397 \\
\hline Community participant & $6(40)$ & - & $9(60)$ & $2(13.3)$ & - & $13(86.7)$ & .215 & .302 \\
\hline
\end{tabular}




\subsection{Hypothesis Two}

We predicted that older adults with TBI would score significantly lower on WHOQOL100 domains than older adults with orthopaedic injury. Table 3 presents WHOQOL-100 domain scores according to injury type. As demonstrated in Figure 1, the TBI group scored lower than the orthopaedic group for all QOL domains except for spirituality. As demonstrated in Table 3, independent-samples t-test revealed that these were statistically significant differences in each domain except for spirituality. Each domain with a significant difference between groups also had a large effect size, which are as follows in order of effect size; Independence $(d=1.65, p=<.001)$, Environment $(d=1.49, p=<.001)$, Psychological $(d=1.36, p=.001)$, Physical $(d=1.35, p=.001)$ and Social Relationships $(d=1.27, p=$ .002). The independence domain demonstrated the largest differences between the TBI $(\mathrm{M}=$ $12.60, \mathrm{SD}=2.96)$ and the orthopaedic groups $(\mathrm{M}=16.87, \mathrm{SD}=2.15, d=1.65, p=<.001)$. For the spirituality domain, TBI participants scored slightly higher $(\mathrm{M}=13.73, \mathrm{SD}=5.28)$

Table 3

WHOQOL-100 Domain Scores After Injury According to Injury Type

\section{$\underline{\text { TBI }(n=15) \quad \text { Orthopaedic }(n=15)}$}

\begin{tabular}{lcccccc} 
Domains & $M$ & $S D$ & $M$ & $S D$ & $p$ & $d$ \\
\hline Physical & 11.27 & 3.56 & 15.48 & 2.62 & $.001^{* *}$ & 1.35 \\
Psychological & 12.68 & 2.39 & 15.31 & 1.35 & $.001^{* *}$ & 1.36 \\
Independence & 12.60 & 2.96 & 16.87 & 2.15 & $<.001 * * *$ & 1.65 \\
Social Relationships & 12.52 & 2.88 & 15.64 & 1.95 & $.002 * *$ & 1.27 \\
Environment & 14.47 & 2.55 & 17.43 & 1.20 & $<.001 * * *$ & 1.49 \\
Spirituality & 13.73 & 5.28 & 12.33 & 4.53 & .443 & .28
\end{tabular}

Note: $\mathrm{M}=$ Mean, $\mathrm{SD}=$ Standard Deviation, $d=$ Cohens d. $p<0.05=* ; p<0.01=* * ; p<0.001 * * *$ 
than orthopaedic participants $(\mathrm{M}=12.33, \mathrm{SD}=4.53)$, however, this result did not reach significance $(d=0.28, p=.443)$. 


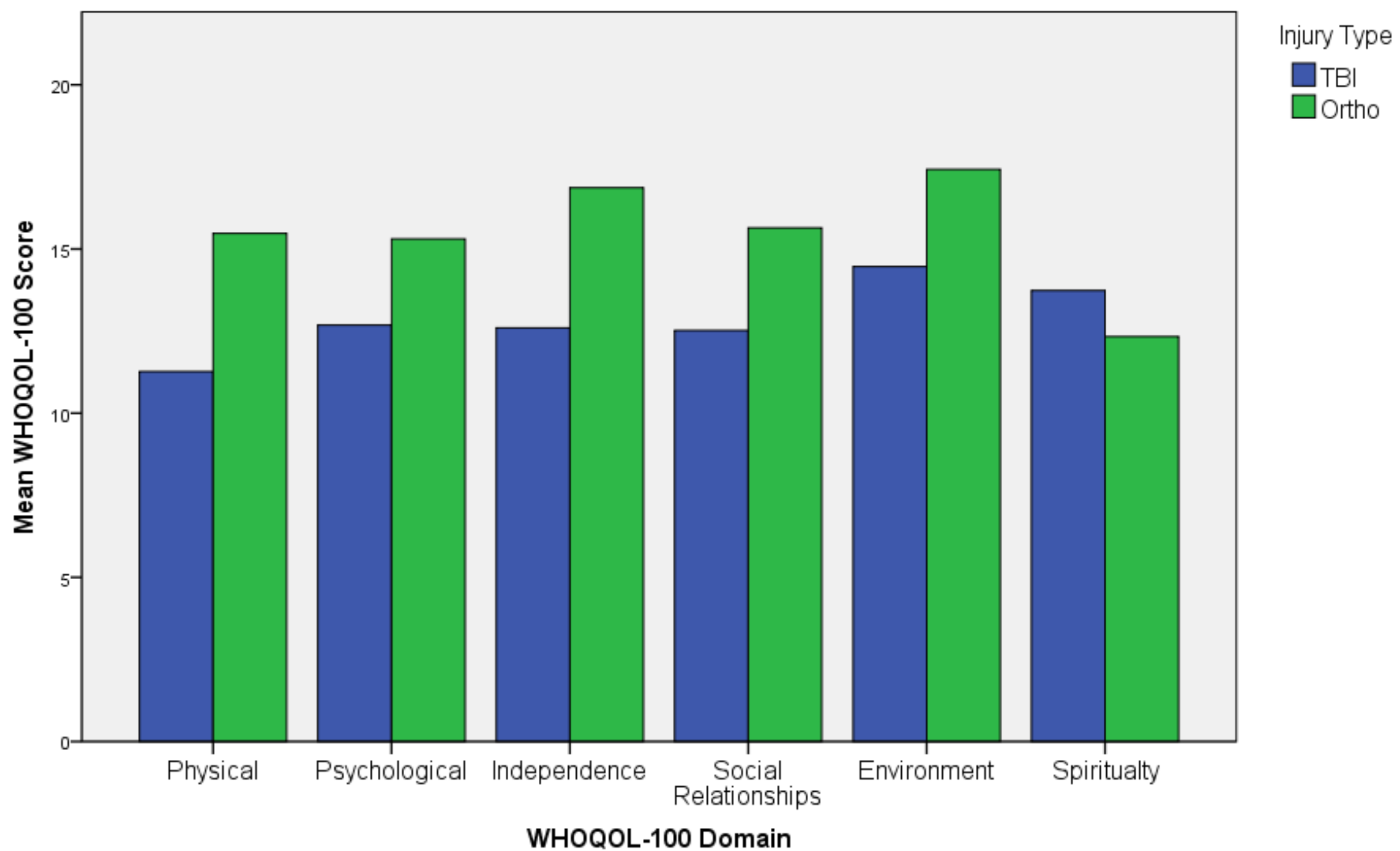

Figure 2. Mean WHOQOL-100 Domain Scores after Injury According to Injury Type 
3.3.1 Hierarchical multiple regressions. Hierarchical regression was used to assess the ability of injury type to predict WHOQOL-100 domain scores after controlling for the influence of age at time of injury, time since injury and sex. Preliminary analyses were conducted to ensure that the assumptions of normality, linearity, lack of mulitcollinearity and homoscedasticity were not violated. As indicated in Table 4, correlations showed that injury type was most strongly related to WHOQOL-100 score, and was the only variable that demonstrated significant relationships with every WHOQOL-100 domain.

Table 4

Correlations of WHOQOL-100 Domain Scores with Covariates After Injury

\section{Covariates}

Domain Sex Age at Injury Time Since Injury Type

Injury

\begin{tabular}{lcccc}
\hline Physical & $.363 *$ & $.551 * *$ & -.149 & $.572 * * *$ \\
Psychological & $.391 *$ & $.314^{*}$ & -.244 & $.574 * * *$ \\
Independence & $.318^{*}$ & $.370^{*}$ & -.029 & $.649 * * *$ \\
Social Relationships & .171 & .119 & -.017 & $.549 * *$ \\
Environment & $.327 *$ & .288 & -.015 & $.609 * * *$ \\
\end{tabular}

Note: $p<0.05=* ; p<0.01=* * ; p<0.001 * * *$ (one tailed)

Analyses revealed multicolinearity between current age and age at time of injury. For example, when including both variables in the regression for the physical domain, multicolinearity was demonstrated as the correlation for age and age at time of injury was .980 , tolerance for age was .054 and age at time of injury was .034 (tolerance below .10 
indicates multicolinearity (Pallant, 2013)). Thus, current age was discarded as a predictor and age at time of injury was retained because age at time of injury did not differ significantly between groups. Additionally, including age at time of injury instead of current age was considered to be more appropriate for the aims of this study. After removing current age, tolerance for age at time of injury was .493 . For each regression, age, time since injury and sex were entered at step one, and injury type was entered at step two. Results (as seen in table 5) for each domain are as follows;

WHOQOL-100 Physical. Age at time of injury, time since injury and sex explained $53.8 \%$ of the variance in physical QOL. After entry of injury type $(1=\mathrm{TBI}, 2=$ orthopaedic $)$ the total variance explained by the model as a whole was $59.8 \%$. Injury type explained an additional $6 \%$ of the variance in WHOQOL-100 physical after controlling for age at time of injury, time since injury and sex, which was not a statistically significant change, $\Delta R^{2}=.060$, $\mathrm{F}(1,25)=3.74, p=.065)$. In the final model, injury type was the only variable that did not make a unique statistically significant contribution to the variance in WHOQOL-100 Physical. In order of importance (according to their beta values) these statistically significant predictor variables are: age at time of injury $(\beta=.64 p=.002)$, sex $(\beta=.46, p=.015)$ and time since injury $(\beta=.56, p=.015)$.

WHOQOL-100 Psychological. Age at time of injury, time since injury and sex explained $21.4 \%$ of the variance in psychological QOL. After entry of injury type at step two, the total proportion of variance explained by the model was $41 \%$. Injury type explained an additional $19.6 \%$ of the variance in psychological QOL, which was a statistically significant difference, $\Delta R^{2}=.20, \mathrm{~F}(1,25)=8.33, p=.008$. In the final model, only injury type was significantly related to WHOQOL-100 Psychological $(\beta=.51, p=.008)$. 
WHOQOL-100 Independence. Age at time of injury, time since injury and sex explained $40.4 \%$ of the variance in independence QOL. After entry of injury type at step two, the total variable explained by the model as a whole was $56 \%$. Injury type explained an additional $15.7 \%$ of the variance in independence QOL, which was statistically significant, $\Delta R^{2}=.15, \mathrm{~F}(1,25)=8.92, p=.006$. In the final model, three variables made a unique statistically significant contribution to the variance of WHOQOL-100 Independence. In order of importance according to beta these were time since injury $(\beta=.52, p=.030)$, injury type $(\beta=.46, p=.006), \operatorname{sex}(\beta=.44, p=.025)$. The only variable that did not make a significant contribution was age at time of injury, although it trended towards significance, $(\beta=.52, p=$ $.056)$

WHOQOL-100 Social Relationships. Age at time of injury, time since injury and sex explained $7.2 \%$ of the variance in social relationships QOL. After entry of injury type at step two, the total variance explained by the model as a whole was $31.7 \%$. Injury type explained an additional $24.5 \%$ of the variance in social relationship QOL, which was a statistically significant difference, $\Delta R^{2}=.245, \mathrm{~F}(1,25)=8.96, p=.006$. In the final model, only injury type was statistically significant in making a unique contribution to the variance of WHOQOL-100 social relationships $(\beta=.57, p=.006)$.

WHOQOL-100 Environment. Age at time of injury, time since injury and sex explained 34\% of the variance in environment QOL. After entry of injury type at step two, the total variance explained by the model as a whole was $49.3 \%$. Injury type explained an additional $15.2 \%$ of the variance in environment QOL, which was a statistically significant difference, $\Delta R^{2}=.15, \mathrm{~F}(1,25)=7.51, p=.011$. In the final model, two variables were statistically significant in making a unique contribution to the variance of WHOQOL-100 
CHANGE IN LIFE ROLE IN OLDER ADULTS AFTER INJURY

environment, with sex recording a slightly higher beta value $(\beta=.46, p=.029)$ than injury type $(\beta=.45, p=.011)$. 
CHANGE IN LIFE ROLE IN OLDER ADULTS AFTER INJURY

Table 5

Summary of Hierarchical Regression Analyses for Injury Type predicting QOL After Injury Whilst Controlling for Other Variables

\begin{tabular}{|c|c|c|c|c|c|c|}
\hline Domains & Model & Variable & $\beta$ & $\mathrm{t}$ & $\mathrm{p}$ & $\mathrm{R}^{2}$ \\
\hline \multirow[t]{9}{*}{ Physical } & 1 & Sex & .563 & 3.169 & $.004 * *$ & \multirow{3}{*}{.538} \\
\hline & & Age at Injury & .797 & 4.701 & $<.001 * * *$ & \\
\hline & & Time Since Injury & .706 & 3.335 & $.003 * *$ & \\
\hline & \multirow[t]{6}{*}{2} & Sex & .463 & 2.621 & $.015^{*}$ & \multirow{4}{*}{.598} \\
\hline & & Age at Injury & .641 & 3.547 & $.002 * *$ & \\
\hline & & Time Since Injury & .562 & 2.614 & $.015^{*}$ & \\
\hline & & Injury Type & .282 & 1.933 & .065 & \\
\hline & & $\Delta R^{2}$ & .060 & & & \\
\hline & & F Change & .065 & & & \\
\hline \multirow[t]{3}{*}{ Psychological } & \multirow[t]{3}{*}{1} & Sex & .444 & 1.919 & .066 & \multirow[t]{3}{*}{.214} \\
\hline & & Age at Injury & .313 & 1.414 & .169 & \\
\hline & & Time Since Injury & .238 & .862 & .397 & \\
\hline
\end{tabular}


CHANGE IN LIFE ROLE IN OLDER ADULTS AFTER INJURY

Table 5 continued

Summary of Hierarchical Regression Analyses for Injury Type predicting QOL After Injury Whilst Controlling for Other Variables continued

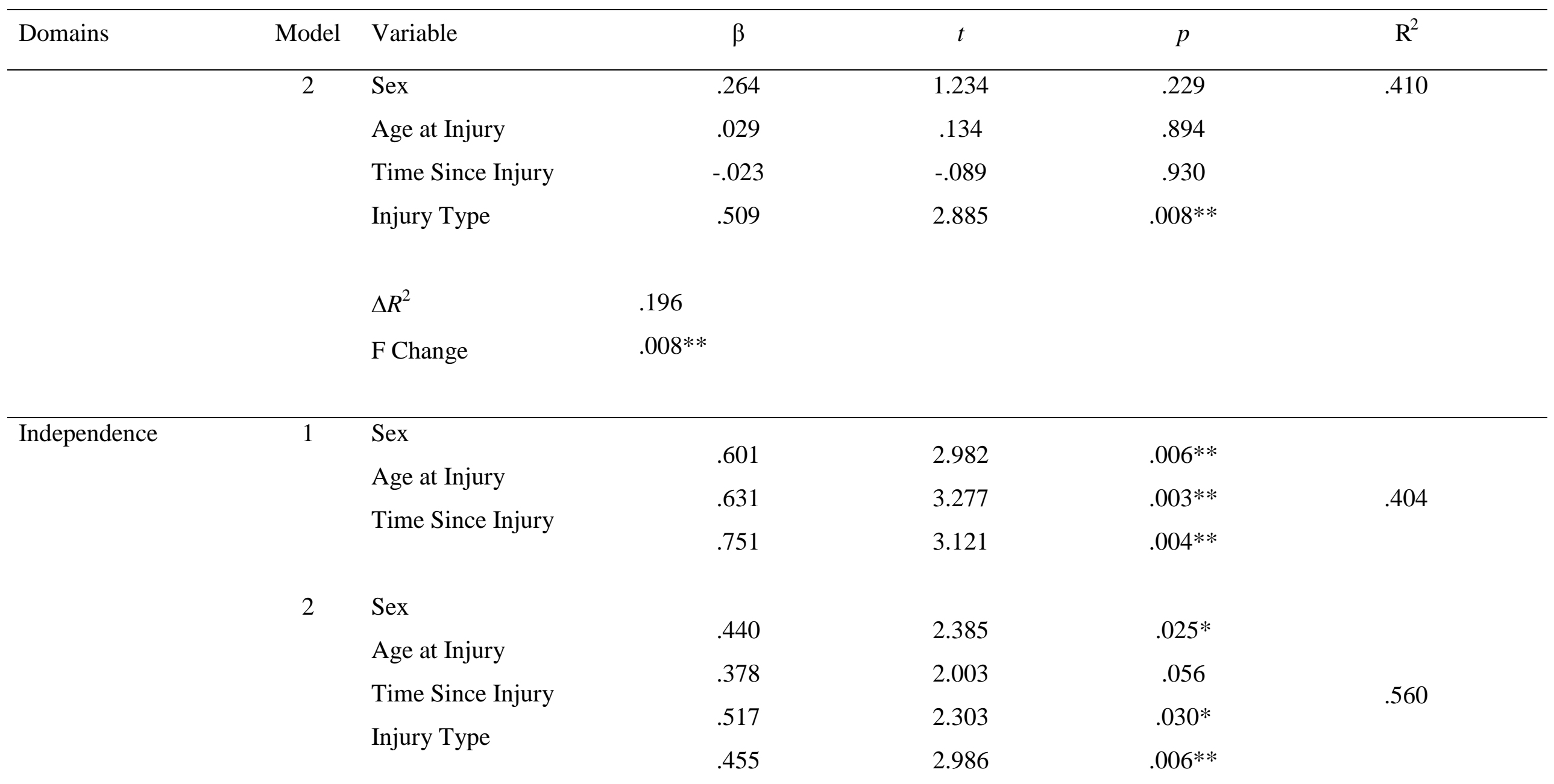


CHANGE IN LIFE ROLE IN OLDER ADULTS AFTER INJURY

Table 5 continued

Summary of Hierarchical Regression Analyses for Injury Type predicting QOL After Injury Whilst Controlling for Other Variables continued

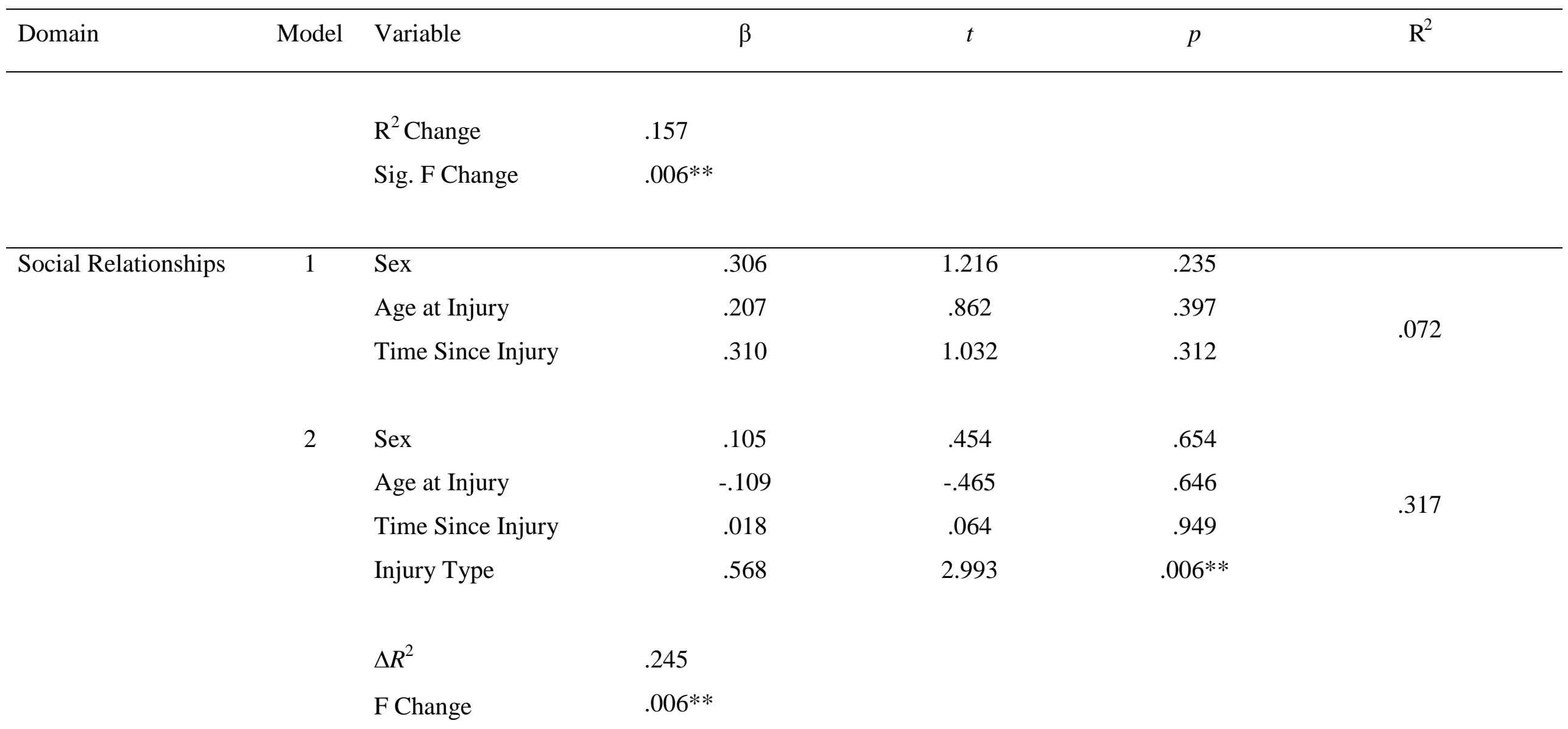


CHANGE IN LIFE ROLE IN OLDER ADULTS AFTER INJURY

Table 5 continued

Summary of Hierarchical Regression Analyses for Injury Type predicting QOL After Injury Whilst Controlling for Other Variables continued

\begin{tabular}{|c|c|c|c|c|c|c|}
\hline Domain & Model & Variable & $\beta$ & $t$ & $p$ & $\mathrm{R}^{2}$ \\
\hline \multirow[t]{9}{*}{ Environment } & 1 & Sex & .618 & 2.914 & $.007 * *$ & .340 \\
\hline & & Age at Injury & .516 & 2.545 & $.017 *$ & \\
\hline & & Time Since Injury & .705 & 2.785 & $.010 *$ & \\
\hline & 2 & Sex & .459 & 2.315 & $.029 *$ & .493 \\
\hline & & Age at Injury & .266 & 1.311 & .202 & \\
\hline & & Time Since Injury & .475 & 1.966 & .060 & \\
\hline & & Injury Type & .448 & 2.741 & $.011^{*}$ & \\
\hline & & $\Delta R^{2}$ & .152 & & & \\
\hline & & F Change & $.011 *$ & & & \\
\hline
\end{tabular}

Note: $p<0.05=* ; p<0.01=* * ; p<0.001 * * * . \Delta R^{2}=\mathrm{R}^{2}$ Change, $\beta=$ Beta. 


\subsection{Hypothesis Three}

We predicted that older adults with TBI would report less satisfaction with their ability to perform activities of daily living than older adults with orthopaedic injury. Table 6 presents satisfaction with ability to perform daily activities scores according to injury type. An independent-samples t-test was conducted to compare daily activities satisfaction scores for TBI and orthopaedic groups. There were significant differences in scores between TBI and orthopaedic groups across all activities, with the TBI group reporting lower satisfaction with their ability to perform daily activities than the orthopaedic group. The activity of shopping demonstrated the largest difference in satisfaction between the TBI $(\mathrm{M}=3.23, \mathrm{SD}=1.36)$ and the orthopaedic groups $(\mathrm{M}=4.85, \mathrm{SD}=0.55), \mathrm{t}(24)=4.12, d=1.595, p=.001,$. A large effect size as measured by Cohens d of 1.595 indicates a large magnitude of difference between the two groups. The smallest effect size of all the activities was .832 for laundry; however, this effect size is still considered large. 
Table 6

Scores of Satisfaction with Ability to do Daily Activities After Injury According to Injury Type

\begin{tabular}{|c|c|c|c|c|c|c|}
\hline & \multicolumn{2}{|c|}{$\underline{\mathrm{TBI}}(n=14)$} & \multicolumn{2}{|c|}{ Orthopaedic $(n=13)$} & \multirow[b]{2}{*}{$p$} & \multirow[b]{2}{*}{$d$} \\
\hline & M & $\mathrm{SD}$ & $\mathrm{M}$ & $S D$ & & \\
\hline Use of phone/other communications & 4.00 & 1.30 & 4.85 & 0.55 & $.039 * *$ & .852 \\
\hline Shopping & 3.23 & 1.36 & 4.85 & 0.38 & $.001 * *$ & 1.595 \\
\hline Food preparation and clean up & 4.07 & 0.92 & 5.00 & 0.00 & $.002 * *$ & 1.402 \\
\hline Housekeeping & 3.45 & 1.21 & 4.54 & 0.52 & $.016 * *$ & 1.155 \\
\hline Laundry & 4.50 & 0.85 & 5.00 & 0.00 & $.047^{\dagger * *}$ & .832 \\
\hline Transportation within the community & 3.71 & 1.38 & 4.92 & 0.28 & $.006 * * *$ & 1.193 \\
\hline Taking medication as prescribed & 4.69 & 0.48 & 5.00 & 0.00 & $.040 * *$ & .896 \\
\hline Managing money & 3.67 & 1.44 & 5.00 & 0.00 & $.008 * *$ & 1.281 \\
\hline Caring for others & 3.77 & 1.17 & 5.00 & 0.00 & $.002 * *$ & 1.458 \\
\hline
\end{tabular}

Note: $\uparrow$. Levene's test indicates that variance for groups not equal therefore Equal Variances Not Assumed t value used to calculate significance

(Pallant, 2013). $\mathrm{M}=$ Mean, $\mathrm{SD}=$ Standard Deviation, $d=$ Cohens d. $p<0.05=* ; p<0.01=* * ; p<0.001 * * *$ 


\subsection{Hypothesis Four}

We predicted that older adults with TBI would be more likely to perceive a negative experience of their recovery and support available when compared with older adults with orthopaedic injury. There were four main themes that emerged when coding the qualitative interviews from the TBI and orthopaedic groups. Firstly, participants spoke support they received around their recovery and managing their symptoms, as well as their experiences with ACC and how that impacted on their return to work. Secondly participants spoke of the empathy and understanding about their injury that they received from the employers, medical professionals, family and friends. Another theme that emerged was changes individuals had to adjust to, such as the impact the injury has had on the individuals emotional and physical well-being, and how that does or does not limit them on a daily basis. Lastly, the participants talked about the things that they found helpful during their recovery, such as practical strategies and home help.

Overall, the TBI participants were more likely than orthopaedic participants to perceive a negative experience when talking about the support they received and returning to work, and report difficulties in gaining support from services. Conversely, orthopaedic participants were more likely to report a positive experience of the support they received, and were less likely to report any issues around it. Similarly, the TBI group were more likely to report a lack of understanding and empathy around their injury symptoms, whereas the orthopaedic group were more likely to report good empathy and understanding, or not to indicate any issues around this. TBI participants were more likely to report difficulties with changes resulting from their injury such as fatigue, difficulty with housework and relationships suffering, whereas the orthopaedic group were more likely to discuss difficulties with aging. Both groups discussed being limited at work because of their injury, and expressed frustration 
around their symptoms. When discussing what was helpful during recovery, the TBI group were more likely to utilize support groups, use acceptance around their symptoms and found hearing that their symptoms were normal helpful. The TBI group also expressed how much they valued being given practical strategies to cope with their symptoms. The orthopaedic group were more likely to use medical aids such as crutches, to find physiotherapy helpful and had home help during their recovery. A full list of themes and codes that emerged from the data is presented in Table 7, and each theme will now be discussed in more detail. 
CHANGE IN LIFE ROLE IN OLDER ADULTS AFTER INJURY

Table 7

Emergent Codes and Themes From Qualitative Data

\begin{tabular}{|c|c|c|c|c|c|}
\hline Theme & Code & $\begin{array}{c}\text { TBI } \\
n(\%)\end{array}$ & $\begin{array}{l}\text { Orthopaedic } \\
n(\%)\end{array}$ & $p$ & $\phi$ \\
\hline \multirow[t]{13}{*}{ Experience of Support } & Negative overall experience & $6(42.9)$ & - & $.016^{*}$ & .515 \\
\hline & Positive overall experience & $5(35.7)$ & $11(84.6)$ & $.018 *$ & .497 \\
\hline & ACC negative experience & $8(57.1)$ & - & $.002 * *$ & .625 \\
\hline & ACC positive experience & $4(28.6)$ & $10(76.9)$ & $.021 *$ & .484 \\
\hline & Fight for ACC Support & $5(35.7)$ & - & $.041 *$ & .459 \\
\hline & ACC Support difficult to instigate & $7(50)$ & - & $.006 * *$ & .570 \\
\hline & ACC support came too late & $2(14.3)$ & - & .481 & .273 \\
\hline & Negative experience of ACC Caseworkers & $1(7.1)$ & - & 1.00 & 189 \\
\hline & Positive experience of ACC Caseworkers & $1(7.1)$ & $4(30.8)$ & .165 & .304 \\
\hline & Mixed experience of ACC Caseworkers & $3(21.4)$ & - & .222 & .341 \\
\hline & Referral processes difficult & $7(50)$ & $1(7.7)$ & $.033^{*}$ & .463 \\
\hline & Pressure to Return to Work & $5(37.7)$ & $1(7.7)$ & .098 & .337 \\
\hline & No Pressure to Return to Work & $1(7.1)$ & $4(30.8)$ & .165 & .304 \\
\hline
\end{tabular}


CHANGE IN LIFE ROLE IN OLDER ADULTS AFTER INJURY

Table 7 Continued

Emergent Codes and Themes From Qualitative Data

\begin{tabular}{|c|c|c|c|c|c|}
\hline Theme & Code & $\begin{array}{c}\text { TBI } \\
n(\%)\end{array}$ & $\begin{array}{c}\text { Orthopaedic } \\
n(\%)\end{array}$ & $p$ & $\phi$ \\
\hline & Issues Returning to Work & $4(28.6)$ & $2(15.4)$ & .648 & .158 \\
\hline & Support services not working towards clients goals & $2(14.3)$ & - & .481 & .273 \\
\hline & Not enough information about their injury & $3(21.4)$ & $1(7.7)$ & .596 & .193 \\
\hline & Clients received unclear diagnosis & $2(14.3)$ & - & .481 & .157 \\
\hline Perceived understanding & No understanding of symptoms from support services & $9(64.3)$ & - & $<.001 * * *$ & .681 \\
\hline and empathy around & No understanding of symptoms from employer or colleagues & $4(28.6)$ & - & .098 & .402 \\
\hline \multirow[t]{4}{*}{ symptoms } & Family and friends were supportive & $7(50)$ & $9(69.2)$ & .440 & .196 \\
\hline & Employer understanding and supportive & $2(14.3)$ & $4(30.3)$ & .286 & .198 \\
\hline & Symptoms not believed & $4(28.6)$ & - & .098 & .402 \\
\hline & Symptoms blamed on other conditions & $4(28.6)$ & - & .098 & .402 \\
\hline \multirow[t]{3}{*}{ Adjusting to change } & Fatigue & $14(100)$ & $1(7.7)$ & $<.001 * * *$ & .982 \\
\hline & Difficulties of body getting older & $1(7.1)$ & $3(23.1)$ & .326 & .224 \\
\hline & Has to plan rest & $1(7.1)$ & - & 1.000 & . 189 \\
\hline
\end{tabular}


CHANGE IN LIFE ROLE IN OLDER ADULTS AFTER INJURY

Table 7 Continued

Emergent Codes and Themes From Qualitative Data

\begin{tabular}{|c|c|c|c|c|c|}
\hline Theme & Code & $\begin{array}{c}\text { TBI } \\
n(\%)\end{array}$ & $\begin{array}{c}\text { Orthopaedic } \\
n(\%)\end{array}$ & $p$ & $\phi$ \\
\hline & Memory issues & $4(28.6)$ & - & .098 & .402 \\
\hline & Housework difficult & $12(85.7)$ & $5(38.5)$ & $.018 *$ & .489 \\
\hline & Disappointed in inability to return to work & $3(21.4)$ & - & .222 & .341 \\
\hline & Is limited at work because of injury & $6(42.9)$ & $2(15.4)$ & .209 & .301 \\
\hline & Family and friend relationships impacted & $9(64.3)$ & - & $.001 * *$ & .681 \\
\hline & Expressed frustration at their injury symptoms & $8(57.1)$ & $5(38.5)$ & .449 & .187 \\
\hline What helped during & Support groups are helpful & $4(28.6)$ & - & .098 & .402 \\
\hline \multirow[t]{6}{*}{ recovery? } & Normalisation is helpful & $4(28.6)$ & - & .098 & .402 \\
\hline & Acceptance of symptoms helps recovery & $5(35.7)$ & - & $.041 *$ & .459 \\
\hline & Practical strategies are helpful & $5(35.7)$ & - & $.041 *$ & .459 \\
\hline & Were not provided with practical strategies & $5(35.7)$ & $1(7.7)$ & .165 & .337 \\
\hline & Enjoy making a valued contribution and keeping busy & $5(35.7)$ & - & $.041 *$ & .459 \\
\hline & Had home help & - & $4(30.8)$ & $.041 *$ & .433 \\
\hline
\end{tabular}


CHANGE IN LIFE ROLE IN OLDER ADULTS AFTER INJURY

Table 7 Continued

Emergent Codes and Themes From Qualitative Data

\begin{tabular}{|c|c|c|c|c|c|}
\hline Theme & Code & $\begin{array}{c}\text { TBI } \\
n(\%)\end{array}$ & $\begin{array}{c}\text { Orthopaedic } \\
n(\%)\end{array}$ & $p$ & $\phi$ \\
\hline & Found physiotherapy helpful & $2(14.3)$ & $9(69.2)$ & $.005^{* *}$ & .559 \\
\hline & Found occupational therapy helpful & $3(21.4)$ & - & .124 & .341 \\
\hline & Used medical aids & - & $6(46.2)$ & $.006 * *$ & .555 \\
\hline
\end{tabular}

Note: $p<0.05=* ; p<0.01=* * ; p<0.001 * * *$ TBI $n=14$, Orthopaedic $n=13 . \phi=$ Phi Coefficient. 
3.6.1 Experience of Support. The TBI group were more likely to report perceiving a negative experience with the support provided than the orthopaedic group, with $42 \%$ of the TBI group and none of the orthopaedic group reporting an overall negative experience when asked how well supported they were through their recovery $(\phi=.515, p=.016)$. Conversely, $84.6 \%$ of orthopaedic participants reported that overall they perceived they were well supported after their injury, compared to only $35.7 \%$ of TBI participants $(p=.018)$ and produced a large effect size $(\phi=.497)$. In particular, the TBI group $(57.1 \%)$ were more likely to perceive a negative experience with ACC; "My experience was a disaster... I felt because the rehabilitation people were under contract to $\mathrm{ACC}$, they were fulfilling their obligation to ACC more than they were fulfilling what was good for me." None of the orthopaedic group reported perceiving an overall negative experience of ACC $(\phi=.625, p=.002)$. In contrast to this, the orthopaedic group (76.9\%) were more likely to report an overall positive experience with the support they received from ACC; "My experience with ACC was absolutely superb" and "I felt totally supported by ACC, I had a wonderful case manager". However, only $28.6 \%$ of the TBI group reported perceiving an overall positive experience of ACC, which was a statistically significant difference $(\phi=.484, p=.021)$.

Those in the TBI group often likened getting the help they needed from ACC as a fight or a battle, such as 'I'm still fighting for (support) and I'll still be fighting for it in another 6 or 7 years" and "I was battling ACC, I was battling the medical people...". In the TBI group $35 \%$ made this comparison, whereas none of the orthopaedic group made the same comparison $(\phi=.495, p=.041)$. In addition, $50 \%$ of the TBI group said that support from ACC was difficult to instigate; "I got given occupational therapy, mind you, you have to ask and plead (ACC) for everything". No orthopaedic participants mentioned difficulties around 
instigating ACC support $(\phi=.570, p=.006)$. Additionally, $14.3 \%$ of TBI participants also reported wondering if their outcomes had been better if ACC had supported them sooner.

Something often discussed in the TBI group was the experience of their ACC caseworker. In the TBI group $7.1 \%$ reported a positive experience of their case manager, $7.1 \%$ reported a bad experience of their case manager and $21.4 \%$ reported that they had both good and bad case managers. When describing what made a bad case manager, it was often that the case manager did not understand the difficulties associated with TBI, and did not adjust their handling of that person accordingly:

I've had some really good case managers and some really bad ones... I had this case manager that, I don't know if she hadn't been trained in brain injury or what but she would send me the same piece of paperwork by post, email and courier, and it had all their reference numbers on it and not mine and I didn't know what was going on so I was so confused.

Within the orthopaedic group, 30.8\% participants described their casework in a positive way, and no one in the orthopaedic group reported a bad experience or mixed experiences of their caseworkers.

Another way in which the TBI group found support difficult to obtain was that the referral processes were not streamlined. Individuals reported they had to go back and forth between different healthcare providers before they could get the support they needed, and $50 \%$ of TBI participants mention difficulties around having to go back and forth between organisations. For example, one TBI participant said:

When I had to go and get a doctors certificate I would go and see him and he would tell me to go to the hospital, and then they would tell me to go back to my GP, so sometimes it would be back and forth 3 times before just for a medical certificate, and I had to pay each time. 
Another participant in the TBI group mentioned how they were given ACC forms to complete, however were not given any information on who these forms were to go or why they should fill them out, so the person did not complete them and therefore did not receive any support around their TBI. In comparison, only $7.7 \%$ of the orthopaedic group spoke about difficulties in who to contact to get the help that they needed $(\phi=.463, p=.033)$.

Another comment often made by the TBI group was around being pressured into returning to work sooner than they were ready to, with $37.7 \%$ of the TBI talking about this; "they pushed me too far too fast, I suppose at the time they needed to find boundaries and how far I could go, but I found that they pushed me too far and it was a disaster". However, the orthopaedic group were less likely to report this $(7.7 \%, \phi=.337, p=.098)$. In contrast to this, the orthopaedic group (30.8\%) were more likely to specifically report not being rushed into returning to work before they were ready; "They didn't pressure me in any way to get back to work because they knew I would get better in my own time and they deal with this a lot so that was really good too". The TBI group were less likely to specifically report perceiving that they weren't being pressured into returning to work $(7.1 \%, \phi=.304, p=$ .165). Not only did the TBI group often perceive that they were being pressured into going back to work early, $14.4 \%$ also reported that they felt as though their healthcare providers were working with the sole purpose of that person returning to work, and not taking into account any of the personal goals that person may have. One participant described this experience:

I got this rehab plan in the mail which had no input from me and said my goal was to return to work. I said this is wrong...my goal is to return to my former abilities as much as I'm able... but she would not change my goal. It felt like she was not trying to rehab me, she was trying to bully me back to work. 


\section{CHANGE IN LIFE ROLE IN OLDER ADULTS AFTER INJURY}

This often led to TBI participants feeling like they were not being heard through their rehabilitation process, and was the source of some frustration for some individuals. One TBI participant talked about their experience when trying to resolve their vertigo:

(The neuropsychologist) would say well it tests ok, and I would say I don't care how it tests, this is how it is for me... I've since found that this was all geared towards ACC, because ACC said I should be back at work, they were just trying to get me to return to work...that's why all the processes were geared towards ACC and not what I say.

On the other hand, there were no participants in the orthopaedic group which expressed concern around pressure to return to work from healthcare providers, and only $15.4 \%$ (and $28.6 \%$ of TBI participants) mentioned any issues around getting back to their normal work schedule, and all orthopaedic participants spoken with eventually did completely return to work. An orthopaedic participant described their experience with physiotherapy and working towards their goal of getting back into outdoors activity in this way:

Physio was awesome...everybody knows I'm wanting to get out and back onto the hills, so that seems to be the focus with physio in general.

Everyone pushed me to get back onto the bike as soon as possible, no one said take it easy.

TBI participants were slightly more likely to report that they did not receive enough information about their injury (21.4\%), whereas orthopaedic participants were less likely to report this $(7.7 \%)$, although this difference was not statistically significant $(\phi=.193, p=$ .596). In the TBI group, $14.3 \%$ reported receiving an unclear diagnosis around their injury, whereas no orthopaedic participants reported this $(\phi=.157, p=.481)$. Other TBI participants talked about being given information leaflets, but did not feel they got the information they needed from the leaflets: 
They told me mild concussion and gave me heaps of pamphlets and that was it... then I got an occupational therapist and I actually sat in with her but I'm not sure what the benefits were because... it was just talking. I got lots of pamphlets though! The information for myself was very poor, I wasn't actually getting told what's wrong with me.

3.6.2 Perceived understanding and empathy around symptoms. A consistent theme that emerged whilst interviewing TBI participants was that these individuals struggled with others not understanding the ongoing effects of TBI and how that impacted their everyday life, whereas the orthopaedic participants did not appear to struggle with this. Particularly, $64.3 \%$ of the TBI participants discussed ways in which support services did not understand and make adjustments for the way TBI affected cognition and energy levels. For example, one participant described being expected to sit a 2 hour assessment, and was met with resistance when the person said this would be difficult for them due to their attention and fatigue issues. Similarly, other TBI participants discussed being given multiple complex forms to complete which they felt unable to do correctly, and one was refused a face to face meeting when requested instead of phone contact, as the individual found phone calls challenging. In contrast to this, no orthopaedic participants reported difficulties with support services not understanding their symptoms or limitations, which was a statistically significant difference $(\phi=.681, p=<.001)$.

Similarly, $28.6 \%$ of TBI participants described a lack of empathy or understanding from their employer and work colleagues around the deficits TBI can cause, which often led to participants feeling judged or ostracized in their workplace: 
I was a principal at the time and I became ostracised from the rest of my staff. No one would talk to me or sit with me or make conversation or give me anything to do and I basically sat in the dental clinic there for 8 hours a day just looking out the window.

None of the orthopaedic participants reported a lack of empathy or understanding around the ongoing affects of their injury from their employer $(\phi=.402, p=.098)$.

Orthopaedic participants were slightly more likely to discuss their partner, family or friends being more supportive and providing practical help such as transport and meals whilst recovering from their injury, with $69.2 \%$ of orthopaedic participants reporting some form of support from their partner, family or friends; "I felt very supported, I had friends offering me transport... I've never had so much social activity.” However, TBI participants were less likely to mention this, with $50 \%(\phi=.196, p=.440)$ in the TBI group mentioning support from their partner or family, and although this difference was not significant, it is of interest that none of the TBI group spoke of support from their friends, whereas $15.4 \%$ of the orthopaedic group did receive support from friends.

TBI participants were also more likely to experience others not believing their symptoms were real, with $28.6 \%$ of TBI participants reporting this, whereas none of the orthopaedic participants had this experience $(\phi=.402, p=.098)$. A TBI participant said: Then you had the likes of your boss turning around and saying you're putting it on, you're faking, this is just a scam. I kept telling him no. A lot of the difficulties of the recovery was having to mask things.

Similarly, $28.6 \%$ of TBI participants had their TBI symptoms blamed on another medical condition, rather it being accepted as part of the ongoing issues resulting from TBI: 
...whereas ACC said it was physical because I'd had children, which was a load of rubbish because I'd never had any issues with my bladder with my children. It wasn't until I had my most recent brain injury. Or they said it was my age which was frustrating.

None of the orthopaedic group reporting having symptoms from their injury blamed on another medical condition $(\phi=.402, p=.098)$.

3.6.3 Adjusting to change. Another theme that emerged was the physical and emotional changes that had occurred as a result of the injury, and what adjustments the individual has had to make because of it.

The physical changes were much discussed as the individuals with TBI struggled to come to terms with how the injury had impacted their everyday lives. Fatigue was an extremely common problem amongst those with TBI, with $100 \%$ of participants suffering from it after their injury to differing degrees. In some cases the fatigue was extremely limiting, for example, one participant spoke of only having one hour in each day where they didn't feel fatigued; "I can get through the day but I have a window of about an hour which is like fog free, but it gets hard after that". Others found that over time the fatigue had almost resolved and only suffered minimal impacts on their life directly from the fatigue. One way of managing fatigue that was discussed was ensuring they are well rested in the lead up to something that will take some concentration. For example, one TBI participant said that they had planned rest in the lead up to and after our interviews because they knew it would be a struggle for them if they had not. Only $7.7 \%$ of the orthopaedic participants reported fatigue as an issue, which is a statistically significant difference $(\phi=.982, p=<.001)$. Memory problems were another problem that TBI participants $(28.6 \%)$ had issues with (compared with none of the orthopaedic participants reporting this issue). TBI participants spoke of often forgetting what they were doing half way through, forgetting where they had parked the car, 
as well as forgetting the names of common objects. One TBI participant said "knowledge that I had on areas is gone, like years of driving around Auckland and now I don't know anything but the main highway and places I've been a number of times since the accident".

As $67 \%$ of TBI participants (compared with $8 \%$ of orthopaedic participants) reported losing their job after their injury, the loss of employment and early retirement was much talked about in the TBI group. Some TBI participants (21.4\%) expressed disappointment that they weren't able to go back to employment after their injury, for example, one TBI participant said:

If I was able to be working without the accident I would have loved to still be working. My wife turns 65 this year and I was really looking forward to working up until then, that would have been lovely.

None of the orthopaedic group reported disappointment about failure to return to work $(\phi=.341, p=.222)$.Some TBI participants spoke about failed attempts to return to work that eventually led to early retirement and others spoke of not even attempting to return to work:

...not that I ever recovered enough to go back and do my job anyway, I've never been able to work since... I officially retired 2 years after the accident, but in actual fact I hadn't really gone back to work.

Conversely, one TBI participant talked about their newfound spare time since they were not working, which they valued as a positive thing:

You've never had as much time either, now I have a lot more time to look at things like politics and other people views, I spend a lot more time supporting other people in the TBI group. The groups I do things with have changed but I'm really enjoying those groups. 
As changes in employment did not appear to be as much of an issue for those in the orthopaedic group, there were no difficulties around changes in employment status mentioned, rather the orthopaedic group $(15.4 \%)$ sometimes mentioned some physical difficulties that may impede on their ability to fully perform their role at work. However, the TBI group were still slightly more likely to report the same (42.9\%), although this difference was not statistically significant but did produce a small effect size $(\phi=.301, p=.209)$. Along with difficulties in performing work duties fully because of their injury, both groups also discussed housework as something they found harder since their injury, however, the TBI group $(85.7 \%)$ reported this significantly more than the orthopaedic group $(38.5 \%, \phi=.489$, $p=.018)$.

TBI participants were more likely to discuss how friends and family also struggled with the changes they observed in them after the TBI. This often had a negative impact on relationships, and $64.3 \%$ of TBI participants mentioned the detrimental effect the TBI had on their relationships. For example, one participant discussed a decrease in social activity, and said:

Eventually people start to lose interest in keeping contact with you, and even though you still try and keep in contact with emails and texts and stuff you start to feel a nuisance after a while, and so eventually its all gone, They've all moved on with their lives.

Similarly, TBI participants also described how the change in the person after their injury has led to difficulties in their relationships with their partner; "My wife found it really hard because it's not the person she married". These issues also extended to the family unit; "I think it's particularly hard on the family, because they knew the person that I was prior to the injury, and now they've got this person who views things differently". In comparison, none of the orthopaedic participants reported 
CHANGE IN LIFE ROLE IN OLDER ADULTS AFTER INJURY

decreased social contact or changes in their relationships after their injury, which was a statistically significant difference $(\phi=.681, p=.001$.$) .$

Lastly, both groups expressed frustration around their recovery and adjusting to the changes their injury has caused, with the TBI group (57.1\%) reporting this slightly more often than the orthopaedic group $(38.5 \%, \phi=.187, p=.449)$. This frustration in the TBI group was typically around their own physical and cognitive difficulties, such as not being able to be a productive as they used to with activities such a housework; “...even things like I couldn’t even ask for help, I couldn't even plan how to do a simple meal for tea which got really frustrating". In the orthopaedic group, frustration was discussed but it was always within the context of the time it took to be back to full functioning, and was not around any lasting symptoms that were still present.

3.6.4 What helped during recovery? A number of different things emerged for what the participants found helpful to their recovery, or gave them a positive experience during their recovery. For example, $28.6 \%$ of the TBI groups cited support groups as beneficial to them, in that talking to others that understand what they were experiencing aided the individual. They also appreciated that within the support groups there was an understanding that if someone feels fatigued and needed to leave then it was acceptable to do so. One participant also spoke about it being enjoyable to be able to comfortably laugh about how their injury affects them with other people who understand the difficulties; “...I met a lot of other people who had brain injuries and that was really helpful, we could just laugh about what was going on". None of the orthopaedic group mentioned receiving support from support groups $(\phi=$ $.402, p=.098)$. 
Normalisation for the symptoms and emotions that are experienced after TBI also helped those in the TBI group, such as knowing that fatigue is a normal part of recovery after TBI, and not to fight this but rather to rest when their body needs to rest. One TBI participant said:

As soon as I spoke to my GP about (the fatigue) he said look as soon as you feel tired then go to bed. Once he explained that was normal and that to just do what I needed to do then that was good... It took for me to hear that to give myself permission to go back to bed.

Within the TBI group, $28.6 \%$ of participants stated that they felt better once they knew what they were experiencing was normal, whereas the orthopaedic participants did not mention this $(\phi=.402, p=.098)$

A frequently talked about process for the TBI group was around acceptance of their injury, and the limitations that the injury symptoms created, with $35.7 \%$ discussing how acceptance prevented them from getting frustrated when not able to do the things they could do prior to their injury. For example, when asked about their current satisfaction with their ability to perform their life roles, one participant said "I'm extremely satisfied because of my acceptance around it, I had a happy life before and I have a happy life now, its just different”. None of the orthopaedic group discussed the need for acceptance as coping strategy for their symptoms, which was significantly less than the TBI group $(\phi=.459, p=.041)$.

Thirty-five percent of TBI participants also discussed how it was helpful when medical practitioners provided them with practical strategies around how to manage their symptoms, such as taking regular short naps throughout the day, and using mindfulness when dealing with sensory overload; "I went to see (a psychologist) and all I can say is that I would give her $11 / 10$ for the work she did with mindfulness. I've found that extremely valuable to add to 
the toolkit". In contrast, none of the orthopaedic participants specifically mentioned that practical strategies were particularly helpful to them $(\phi=.459, p=.041)$. Additionally, $35.7 \%$ of TBI participants spoke of their frustration when they weren't offered any practical tools to take away:

I had three visits with a neurologist and they just said oh well you're on the right track... after that they just said you're doing fine but they didn't actually give me any suggestions. Once I got to New Zealand I had to pay for my own neurologist, but at least he actually had some suggestions. In contrast to this, only $7.7 \%$ of orthopaedic participants mentioned that they were not provided with enough practical strategies $(\phi=.337, p=.165)$.

Lastly, something that was discussed by $35.7 \%$ of the TBI group was that feeling like they were making a valued contribution, staying busy and having a sense of purpose helped them on a day to day basis when dealing with the difficult realities of their injury related issues. For example, when talking about care giving, one participant said "just being able to get up and do something and being able to concentrate on something helps. Another said "the last thing I want to do is sit at home feeling sorry for myself so I keep myself busy and I plan to do things". Again, none of the orthopaedic group mentioned a need for staying busy or having a purpose to help them on a day to day basis $(\phi=.459, p=.041)$.

For the orthopaedic group, the thing that was most discussed as a help during their recovery was receiving physiotherapy, with $69.2 \%$ of orthopaedic participants reporting that physiotherapy was helpful to them, compared to $14.3 \%$ of TBI patients $(\mathrm{p}=.005, \phi=.559)$. Additionally, orthopaedic participants were more likely to report that they had home help such as someone to do their housework or making meals $(30.8 \%)$, whereas no TBI participants reported having home help at any stage of their recovery $(\mathrm{p}=.041, \phi=.443)$. 
CHANGE IN LIFE ROLE IN OLDER ADULTS AFTER INJURY

Lastly, orthopaedic participants were more like to use medical aids such as crutches or a walking frame after their injury (46.2\%), whereas no TBI participants reported using or being offered to use these $(\mathrm{p}=.006, \phi=.555)$. 


\section{Discussion}

This thesis' aims were to examine whether TBI influenced return to work, other changes in life roles, QOL and daily activities in older adults with TBI, as well as investigating perception of recovery for older people following injury. As expected, results demonstrated that when compared with older adults with orthopaedic injury, older adults after TBI were less likely to return to work, experienced more role losses, perceived a lower QOL, were less satisfied with their ability to perform daily activities and perceived an overall more negative experience of their recovery.

\subsection{Return to work}

Older adults with TBI were significantly less likely to return to work than older adults with orthopaedic injury. The worker role for TBI participants was also the role that had the highest number of role losses of any role for both TBI and orthopaedic participants. It should be noted that as the orthopaedic group were significantly older than the TBI group, the orthopaedic group were closer to retirement age and logically should be more likely to retire after their injury, yet the TBI group still remained more likely to retire or lose the role of worker after their injury. This is consistent with previous findings that older adults with TBI have difficulties in returning to work post-injury (Shames et al., 2007), and are more likely to retire after their injury (Ritchie et al., 2014). Moreover, these results also support similar findings that older adults with TBI are more likely to have a change of employment status post injury than older adults with orthopaedic injury (Testa et al., 2005).

\subsection{Role change}

Older adults with TBI experienced significantly greater total role losses and significantly fewer incidences of no role change than the older adults with orthopaedic injuries. Role change patterns differed significantly for older adults with TBI and orthopaedic injuries for the roles of home maintainer, friend, family member, caregiver, and religious 
participant, where the TBI demonstrated greater role losses than the orthopaedic group and the TBI group demonstrated fewer incidences of no change than the orthopaedic group. These findings support previous research that role change and particularly role losses occur after TBI (Hallett et al., 1994; Sloan et al., 2007), and provides evidence that the same changes are observed specifically in older adults. Similarly, these findings also support evidence that suggests older adults with mild-severe TBI will have more role losses than older adults with another crisis event (Layman et al., 2005), and furthermore this study also demonstrates that said role loss occurs specifically after mild TBI in older adults.

Contrary to previous evidence that community integration is low after TBI (Sloan et al., 2007), community participation demonstrated the least differences between injury groups. Reasons for this difference in findings could be that previous research examined adults of all ages whereas this study looked specifically at older adults, or because different measures of community participation were used.

\subsection{Quality of Life}

QOL was significantly lower for older adults with TBI in the physical, psychological, independence, social relationships and environment domains. After controlling for age at time of injury, time since injury and sex, having TBI predicted lower QOL for each of these domains (physical, psychological, independence, social relationships and environment) except for the physical domain. Whilst previous evidence examining QOL post-TBI in adults of all ages has demonstrated some inconsistent findings, there was a general theme that those with TBI tend to report low QOL (Dijkers, 2004), which is consistent with the results of this current study. As having TBI did not predict lower QOL on all domains in this study, this also suggests, along with previous evidence (Dijkers, 2004), that the relationship between having TBI and a low QOL is complex, and can elicit different results depending on which domain of QOL examined and which measure used. 
Within the physical domain, age at time of injury was the best predictor of QOL, which could be because of the normal effects of aging that would be evident in both groups, which has been discussed in previous literature (Layman et al., 2005). As the nature of orthopaedic injury can be extremely physically limiting, and the orthopaedic group was older, it is logical that having TBI did not predict lower QOL within that domain, and that age would have a bigger influence in this case.

\subsection{Daily Activities}

The TBI group rated their satisfaction with their ability to perform daily activities significantly lower than the orthopaedic group in all daily activities. This is supported by previous studies that demonstrated that older adults with TBI will have more difficulty with 'partnership tasks' which included financial management and household tasks, than older adults who experienced a crisis event (Layman et al., 2005).

\subsection{Perception of recovery}

The TBI group was more likely than the orthopaedic group to report perceiving an overall negative experience of how well they were supported, as well as a reporting difficulties with ACC such as have issues in instigating ACC support for their injury. In contrast to this, the orthopaedic group were more likely to report perceiving an overall positive experience of how well they were supported, and a positive experience of ACC. Additionally, those with TBI were more like than those with orthopaedic injury to describe unclear referral processes when trying to instigate support for themselves. These findings are in agreement with previous evidence suggesting individuals with TBI find accessing support difficult (Sample \& Darragh, 1998), and provides novel information about perception of support and rehabilitation within a New Zealand context and within older adults. Individuals with TBI were also more likely than orthopaedic participants to report feeling like support services did not understand their symptoms, or report a lack of empathy towards their 
symptoms. Darragh et al. (2001) described the importance of the therapeutic relationship and demonstrated empathy from the practitioner, which could suggest why TBI participants were more likely to feel unsupported if they did not experience the same empathy as the orthopaedic group may have.

The qualitative information also demonstrated the changes that the TBI group experienced, for example the TBI group were more likely than the orthopaedic group to report feeling fatigued on a regular basis, as well as having difficulties with completing house work. This is in agreement with previous evidence that suggests older adults with TBI have more difficulties with household tasks than those who had experienced a crisis event (Layman et al., 2005). When discussing the life changes post-injury, TBI participants were also more likely to report that their family and friend relationships had been negatively impacted by their injury, and therefore their social contact was reduced. This is somewhat supported by research examining social contact as part of QOL, which demonstrated that those with TBI have lower QOL.

The TBI group and orthopaedic group also differed significantly on what was helpful to them during their recovery. For example, the TBI group reported that acceptance of injury symptoms, being given practical strategies they could implement, keeping busy and making a valid contribution to their family or wider community was most helpful to them, whereas the orthopaedic group reported that physiotherapy, the use of medical aids such as crutches and home help were most helpful. None of the TBI group reported receiving home help, which is somewhat supported by evidence suggesting that older adults with TBI received less rehabilitative input than their younger counterparts (Dijkers et al., 2013), and that those with TBI had trouble accessing support services (Sample \& Darragh, 1998). 


\subsection{Implications of the Findings}

A number of implications can be identified from the current research. Firstly, that mTBI in older adulthood can lead to early retirement, which with New Zealands' aging population and workforce may have economic implications for the wider community. In addition to the loss of employment, older adults with mTBI can also experience the loss of a number of other important life roles, such as home maintainer, friend, family member, caregiver and religious participant. The ability to perform these life roles, and daily activities, plays an important part in an individual's sense of well-being and perceived QOL, and the loss of these roles after mTBI may contribute to a decrease in QOL, therefore it is important that after mTBI, older adults are adequately supported to maintain their employment and previous life roles. However, this research suggests that within New Zealand, older adults with mTBI are finding it difficult to receive the support they need to do so, and as a result may not be recovering as much or completely as they would have liked to. Moreover, that within New Zealand, older adults with mTBI do not have an equal experience of support services when compared to older adults with orthopaedic injury, leaving older adults with mTBI feeling discriminated against and overlooked by services that are supposed to support them, and that are supporting those with other types of injuries in a satisfactory manner. This inequality in the support available can contribute to the poor QOL in older adults with mTBI, and therefore improvements need to be made to the quality of the help they receive, to enhance functionality and well-being in older adults with mTBI.

\subsection{Strengths}

A major strength of this study is the use of an orthopaedic injury control group rather than a healthy control group. The use of a group with another injury event means that the effects of a traumatic injury such as time off work, hospital stays, rehabilitation processes and trauma are controlled for, and allows the findings of the study to be more attributable to the type of injury, rather than the overall experience of a traumatic event in older adulthood. 
Another strength of the study was the collection of qualitative data. The personal accounts of rehabilitation and recovery added richness and depth to the data that becomes easily lost when utilizing quantities measures alone. The combination of both quantitative and qualitative methods employed in this research ensures a thorough investigation and exploration of the topic, as well as allowing the individuals who have lived the experience to offer their valuable perspective and insights.

\subsection{Limitations}

Some limitations lie in the sample used for this study. The small sample size means that it is difficult to generalise findings to a wider population. Additionally, the orthopaedic groups' current age was significantly older than the TBI groups. Whilst the focus on the study was age at time of injury rather than current age, the orthopaedic control group would have been improved if all other variables except injury type did not differ. Further, whilst using an orthopaedic control group was a strength of this study, a further improvement could have been also including a non-injury control, to further clarify the effects of injury in older adults.

Another area that could have been improved was the procedure for the semi structured interview. As recording of interviews did not have ethical approval, participants responses were noted at the time of the interview and checked with the participant if there were uncertainties. However, recording of the interviews could have ensured further accuracy as it would have allowed the interviewer to re-check their transcripts. Additionally, whilst every effort was made to remain consistent throughout coding, the use of a second coder could have guaranteed the accuracy of the coding.

\subsection{Directions for Future Research}

Although this study has provided novel information on the impact of mTBI on life roles and quality of life within New Zealand, future research could aim to replicate these findings on a larger scale, to provide greater reliability when generalising to the older adult population. 
Similarly, since this study focused specifically on a New Zealand population, it would be of interest to replicate it in other countries, which could help to identify which support methods are more successful than others.

The role of QOL could be further investigated to clarify the exact influence TBI has on older adults QOL after mTBI. As discussed previously, whilst generally those with TBI tend to report lower QOL, the all encompassing definition of QOL means that there are many areas to explore within QOL. Additionally, further research could examine specifically whether changes in QOL are due to age or due to ongoing injury symptoms in older adults with mTBI. Due to the aging population in New Zealand, it is important that further investigation expands on previous research to support well-being in older adulthood.

Future research directions could also include investigation in how best to support older adults with mTBI in order to improve outcomes for the individual as much as possible. Potential research could examine what methods of rehabilitation are most effective for older adults with mTBI within New Zealand, and look towards how to implement these methods within New Zealand.

\subsection{Conclusions}

Outcomes after TBI in older adulthood are an important economic and health issue due to the potential for older adults to suffer life role losses after TBI, including early retirement, which can have a negative impact on their well-being and QOL, and therefore it important that older adults are adequately supported to fully engage in their pre-injury life roles.

The aims of this research were to determine if there were significant differences between life role loss (specifically employment), QOL, satisfaction with ability to perform daily activities, perception of support and rehabilitation experience in older adults with TBI and orthopaedic injuries. The findings indicate that older adults with TBI experienced 
significantly more role losses than those with orthopaedic injury, and that older adults with TBI experienced the most loss in their employment role. Older adults with TBI also had significantly lower QOL and significantly lower satisfaction with their ability to perform daily activities than older adults with orthopaedic injury. Older adults with TBI also significantly more likely than older adults with orthopaedic injury to report a negative experience of the support they received and their recovery.

In conclusion, the findings of this study provide novel information about the experience of rehabilitation and recovery of older adults with TBI in New Zealand, as well as evidence that the specific population of older adults with mTBI experience significant negative changes after injury, such as role losses and poor QOL. These findings highlight the need for services that provide adequate support to the older adult TBI population, so they can return to their pre-injury life roles and maintain a good QOL. 


\section{References}

Andelic, N., Hammergren, N., Bautz-Holter, E., Sveen, U., Brunborg, C., \& Røe, C. (2009). Functional outcome and health-related quality of life 10 years after moderate to severe traumatic brain injury. Acta Neurologica Scandinavica, 120(1), 16-23. doi: 10.1111/j.1600-0404.2008.01116.x

Barker-Collo, S. L., Wilde, N. J., \& Feigin, V. L. (2009). Trends in head injury incidence in New Zealand: a hospital-based study from 1997/1998 to 2003/2004. Neuroepidemiology, 32(1), 32-39. doi: 10.1159/000170090

Bogues, K., \& Wilson, R. (n.d.). The Accessible Role Checklist Retrieved 5 March 2016, from http://www.learningace.com/doc/213256/cac795ce126e42531bd6b15cc8432f8d/acces $\underline{\text { sible-role-checklist }}$

Braun, V., \& Clarke, V. (2006). Using thematic analysis in psychology. Qualitative research in psychology, 3(2), 77-101. doi: 10.1191/1478088706qp063oa

Bruns, J., \& Hauser, W. A. (2003). The epidemiology of traumatic brain injury: a review. Epilepsia, 44(s10), 2-10. doi: 10.1046/j.1528-1157.44.s10.3.x

Chua, K. S., Ng, Y., Yap, S. G., \& Bok, C. (2007). A brief review of traumatic brain injury rehabilitation. Annals-Academy of Medicine Singapore, 36(1), 31.

Cifu, D. X., Kreutzer, J. S., Marwitz, J. H., Rosenthal, M., Englander, J., \& High, W. (1996). Functional outcomes of older adults with traumatic brain injury: a prospective, multicenter analysis. Archives of Physical Medicine and Rehabilitation, 77(9), 883888. doi: Functional outcomes of older adults with traumatic brain injury: a prospective, multicenter analysis

Cohen, J. (1992). A power primer. Psychological bulletin, 112(1), 155. doi: 10.1037/00332909.112.1.155 
CHANGE IN LIFE ROLE IN OLDER ADULTS AFTER INJURY

Coronado, V. G., Thomas, K. E., Sattin, R. W., \& Johnson, R. L. (2005). The CDC traumatic brain injury surveillance system: characteristics of persons aged 65 years and older hospitalized with a TBI. The Journal of head trauma rehabilitation, 20(3), 215-228. doi: 10.1097/00001199-200505000-0000

Darragh, A. R., Sample, P. L., \& Krieger, S. R. (2001). “Tears in My Eyes' Cause Somebody Finally Understood": Client Perceptions of Practitioners Following Brain Injury. American journal of occupational therapy, 55(2), 191-199. doi: 10.5014/ajot.55.2.191

Dijkers, M., Brandstater, M., Horn, S., Ryser, D., \& Barrett, R. (2013). Inpatient rehabilitation for traumatic brain injury: The influence of age on treatments and outcomes. NeuroRehabilitation, 32(2), 233-252. doi: 10.3233/NRE-130841

Dijkers, M. P. (2004). Quality of life after traumatic brain injury: a review of research approaches and findings. Archives of Physical Medicine and Rehabilitation, 85, Supplement 2(0), 21-35. doi: 10.1016/j.apmr.2003.08.119

Feigin, V. L., Theadom, A., Barker-Collo, S., Starkey, N. J., McPherson, K., Kahan, M., .. . Kydd, R. (2012). Incidence of traumatic brain injury in New Zealand: a populationbased study. The Lancet Neurology. doi: 10.1016/S1474-4422(12)70262-4

Glenn, M. B. (2012). Rehabilitation Following TBI. In J. W. Tsao (Ed.), Traumatic Brain Injury (pp. 245-271): Springer New York.

Hallett, J. D., Zasler, N. D., Maurer, P., \& Cash, S. (1994). Role change after traumatic brain injury in adults. The American Journal of Occupational Therapy, 48(3), 241-246. doi: 10.5014/ajot.48.3.241

Heard, C. (1977). Occupational role acquisition: a perspective on the chronically disabled. American journal of occupational therapy.

. Introduction to ACC. (2015, 11 December 2015) Retrieved 28 March 2016, 2016, from http://www.acc.co.nz/about-acc/overview-of-acc/introduction-to-acc/ABA00002 
CHANGE IN LIFE ROLE IN OLDER ADULTS AFTER INJURY

Jacoby, S. F., Ackerson, T. H., \& Richmond, T. S. (2006). Outcome from serious injury in older adults. Journal of Nursing Scholarship, 38(2), 133-140. doi: 10.1111/j.15475069.2006.00090.x

Keyser-Marcus, L. A., Bricout, J. C., Wehman, P., Campbell, L. R., Cifu, D. X., Englander, J., . . Zafonte, R. D. (2002). Acute predictors of return to employment after traumatic brain injury: A longitudinal follow-up. Archives of Physical Medicine and Rehabilitation, 83(5), 635-641. doi: 10.1053/apmr.2002.31605

Kibby, M., \& Long, C. (1999). Effective treatment of mild traumatic brain injury and understanding its neurological consequences. Mild traumatic brain injury: A clinician's guide. Austin, TX: Pro-Ed.

Konrad, C., Geburek, A., Rist, F., Blumenroth, H., Fischer, B., Husstedt, I., . . Lohmann, H. (2011). Long-term cognitive and emotional consequences of mild traumatic brain injury. Psychological medicine, 41(06), 1197-1211. doi:

$10.1017 / \mathrm{S} 0033291710001728$

Langlois, J. A., Rutland-Brown, W., \& Thomas, K. E. (2006a). Traumatic brain injury in the United States: emergency department visits, hospitalizations, and deaths: Department of Health and Human Services, Centers for Disease Control and Prevention, National Center for Injury Prevention and Control.

Langlois, J. A., Rutland-Brown, W., \& Wald, M. M. (2006b). The epidemiology and impact of traumatic brain injury: a brief overview. The Journal of head trauma rehabilitation, 21(5), 375-378. doi: 10.1.1.471.3907

Lawton, M., \& Brody, E. (1988). Instrumental Activities of Daily Living Scale (IADL).

Layman, D., Dijkers, M., \& Ashman, T. (2005). Exploring the impact of traumatic brain injury on the older couple:'Yes, but how much of it is age, I can't tell you...'. Brain Injury, 19(11), 909-923. doi: 10.1080/02699050500109928 
CHANGE IN LIFE ROLE IN OLDER ADULTS AFTER INJURY

Mason, M. (2010). Sample size and saturation in PhD studies using qualitative interviews.

Paper presented at the Forum Qualitative Sozialforschung/Forum: Qualitative Social Research.

McCrea, M. (2008). Mild traumatic brain injury and postconcussion syndrome: The new evidence base for diagnosis and treatment: Oxford University Press, USA.

McCrea, M., Iverson, G. L., McAllister, T. W., Hammeke, T. A., Powell, M. R., Barr, W. B., \& Kelly, J. P. (2009). An integrated review of recovery after mild traumatic brain injury (MTBI): implications for clinical management. Clin Neuropsychol, 23(8), 1368-1390. doi: 10.1080/13854040903074652

McPherson, M. (2015). Older Workers: Challenging Myths and Managing Realities. Retrieved from

O'Connell, A. (2014). Longevity Trends and their Implications for the Age of Eligibility for New Zealand Superannuation: Victoria University of Wellington.

Oakley, F., Kielhofner, G., Barris, R., \& Reichler, R. K. (1986). The Role Checklist: Development and empirical assessment of reliability. OTJR: Occupation, Participation and Health, 6(3), 157-170. doi: 10.1177/153944928600600303

Pallant, J. (2013). SPSS survival manual: McGraw-Hill Education (UK).

Pinquart, M., \& Sörensen, S. (2000). Influences of socioeconomic status, social network, and competence on subjective well-being in later life: A meta-analysis. Psychology and Aging, 15(2), 187-224. doi: 10.1037/0882-7974.15.2.187

Ponsford, J. L., Olver, J., Curran, C., \& Ng, K. (1995). Prediction of employment status 2 years after traumatic brain injury. Brain Injury, 9(1), 11-20. doi:

$10.3109 / 02699059509004566$

Rappaport, M., Hall, K., Hopkins, K., Belleza, T., \& Cope, D. (1982). Disability rating scale for severe head trauma: coma to community. Archives of physical medicine and rehabilitation, 63(3), 118-123. 
CHANGE IN LIFE ROLE IN OLDER ADULTS AFTER INJURY

Resch, J. A., Villarreal, V., Johnson, C. L., Elliott, T. R., Kwok, O.-M., Berry, J. W., \& Underhill, A. T. (2009). Trajectories of life satisfaction in the first 5 years following traumatic brain injury. Rehabilitation Psychology, 54(1), 51. doi: 10.1037/a0015051

Ritchie, L., Wright-St Clair, V. A., Keogh, J., \& Gray, M. (2014). Community Integration After Traumatic Brain Injury: A Systematic Review of the Clinical Implications of Measurement and Service Provision for Older Adults. Archives of Physical Medicine and Rehabilitation, 95(1), 163-174. doi: 10.1016/j.apmr.2013.08.237

Rothweiler, B., Temkin, N. R., \& Dikmen, S. S. (1998). Aging effect on psychosocial outcome in traumatic brain injury. Archives of Physical Medicine and Rehabilitation, 79(8), 881-887. doi: 10.1016/S0003-9993(98)90082-X

Sample, P. L., \& Darragh, A. R. (1998). Perceptions of care access: the experience of rural and urban women following brain injury. Brain Injury, 12(10), 855-874. doi: $10.1080 / 026990598122089$

Shames, J., Treger, I., Ring, H., \& Giaquinto, S. (2007). Return to work following traumatic brain injury: trends and challenges. Disability \& Rehabilitation, 29(17), 1387-1395. doi: 10.1080/09638280701315011

Sloan, S., Winkler, D., \& Anson, K. (2007). Long-term outcome following traumatic brain injury. Brain Impairment, 8(03), 251-261. doi: 10.1375/brim.8.3.251

Statistics New Zealand. (2009). The impact of structural population change. Wellington: Statistics New Zealand. Retrieved from

Stocchetti, N., Paternò, R., Citerio, G., Beretta, L., \& Colombo, A. (2012). Traumatic brain injury in an aging population. Journal of Neurotrauma, 29(6), 1119-1125. doi: 10.1089/neu.2011.1995

Teasdale, G., \& Jennett, B. (1974). Assessment of coma and impaired consciousness: a practical scale. The Lancet, 304(7872), 81-84. doi: 10.1016/S0140-6736(74)91639-0. PMID 4136544. 
Testa, J. A., Malec, J. F., Moessner, A. M., \& Brown, A. W. (2005). Outcome after traumatic brain injury: effects of aging on recovery. Archives of Physical Medicine and Rehabilitation, 86(9), 1815-1823. doi: 10.1016/j.apmr.2005.03.010

The WHOQOL Group. (1998). The World Health Organization quality of life assessment (WHOQOL): development and general psychometric properties. Social science \& medicine, 46(12), 1569-1585. doi: 10.1016/S0277-9536(98)00009-4

Thompson, H. J., McCormick, W. C., \& Kagan, S. H. (2006). Traumatic brain injury in older adults: epidemiology, outcomes, and future implications. Journal of the American Geriatrics Society, 54(10), 1590-1595. doi: 10.1111/j.1532-5415.2006.00894.x

Turner-Stokes, L., Disler, P., Nair, A., \& Wade, D. (2005). Multi-disciplinary rehabilitation for acquired brain injury in adults of working age. Cochrane Database Syst Rev, 3. doi: 10.1002/14651858.CD004170

Watanabe, T. K., Miller, M. A., \& McElligott, J. M. (2003). 5. Outcomes after acquired brain injury. Archives of physical medicine and rehabilitation, 84, S23-S27. doi: 10.1053/apmr.2003.50054

. WHOQOL: Measuring Quality of Life. (2016) Retrieved 12 April 2016, from http://www.who.int/healthinfo/survey/whoqol-qualityoflife/en/

Yi, A., \& Dams-O'Connor, K. (2013). Psychosocial functioning in older adults with Traumatic Brain Injury. NeuroRehabilitation, 32(2), 267-273. doi: 10.3233/NRE130843 
Appendices

Appendix A

\title{
PARTICPANTS WANTED! \\ We are looking for people aged 50-65 who have banged their head (TBI or 'concussion')
}

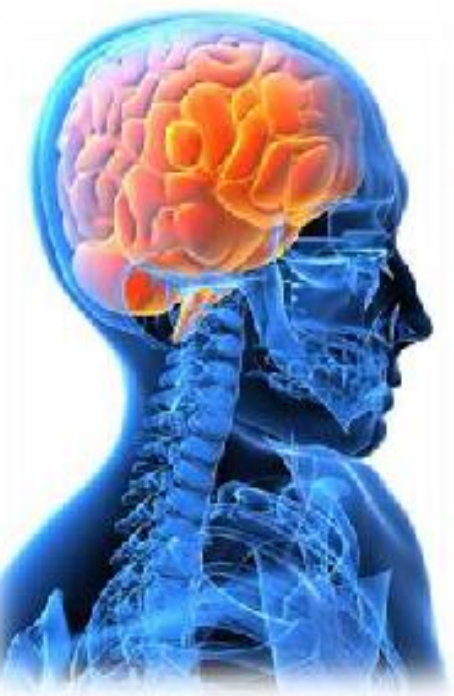

\author{
Volunteers will be part of a project at \\ the University of Canterbury looking at \\ the impact of injury on life roles and \\ quality of life
}

- You will be asked to complete a questionnaire about life roles and another about your quality of life that will be posted to your home

- You will also participate in a short interview over the phone

- It should take approximately $1 \frac{1}{2}$ hours

- We are looking for people who had their injuries at least 6 months ago, but within the ages of 50-65

We will be comparing your experiences with people who haven't had an injury to see what impact injury has on your life roles and quality of life.

You will receive a $\$ 10$ fuel or New World voucher upon completing your interview

If you are interested in participating and would like to know more information then please contact:

\section{Katie Dainter}

Email: katie.dainter@pg.canterbury.ac.nz

Phone: 0226325543

This project has been reviewed and approved by the University of Canterbury Human Ethics Committee 


\section{PARTICPANTS WANTED!}

\section{We are looking for people aged 50-65 who have had a long bone fracture (e.g. a broken arm or leg)}

Volunteers will be part of a project at the University of Canterbury looking at the impact of injury on life roles and quality of life

- You will be asked to complete a questionnaire about life roles and another about your quality of life that will be posted to your home

- You will also participate in a short interview over the phone

- It should take approximately $1 \frac{1 / 2}{2}$ hours overall

- We are looking for people who had their injuries at least 6 months ago, but within the ages of 50-65

We will be comparing your experiences with people who haven't had an injury to see what impact injury has on your life roles and quality of life.

You will receive a $\$ 10$ fuel or countdown voucher upon completing your interview.

If you are interested in participating and would like to know more information then please contact:

Katie Dainter

Email: katie.dainter@pg.canterbury.ac.nz

Phone: 0226325543

This project has been reviewed and approved by the University of Canterbury Human Ethics Committee 


\section{Appendix B}

\section{$\underline{\text { Instructions for Role Checklist }}$}

Please complete this questionnaire. It will ask about the different roles you have in your life currently and before your injury. Please do not spend too much time on any answer, and go with what fits you the best.

Beside each role, indicate by checking the appropriate column, if you performed the role before your injury, if you presently perform the role (over the last week), and if you would like to perform the role. You may check more than one column for each role. For example, if you volunteered in the past, do not volunteer at present, but plan to in the future, you would check the 'before my injury' and 'I would like to do this' columns.

Please also check the column which best indicates how valuable or important the role is to you. Answer for each role, even if you have never performed or do not plan to perform the role.

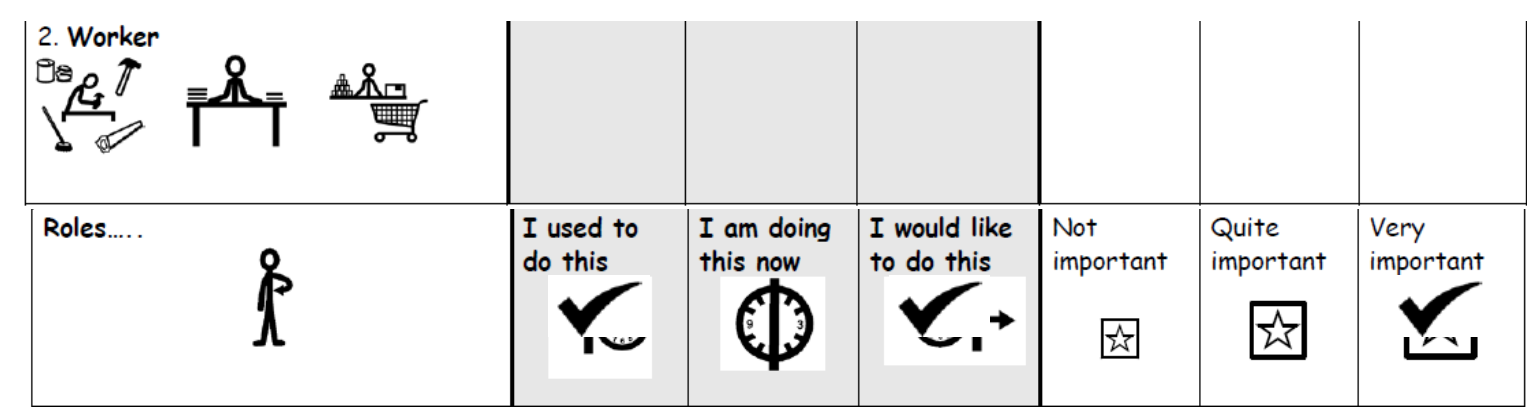

Example: Richard worked as a mechanic until he had an injury which meant he could no

longer work. He really enjoyed being a mechanic and wishes he could go back to his job.

For the 'worker' role Richard might tick that he did this before his injury, and that he would like to do this now. He also might tick that that this role is very important to him. 


\section{Role Checklist}

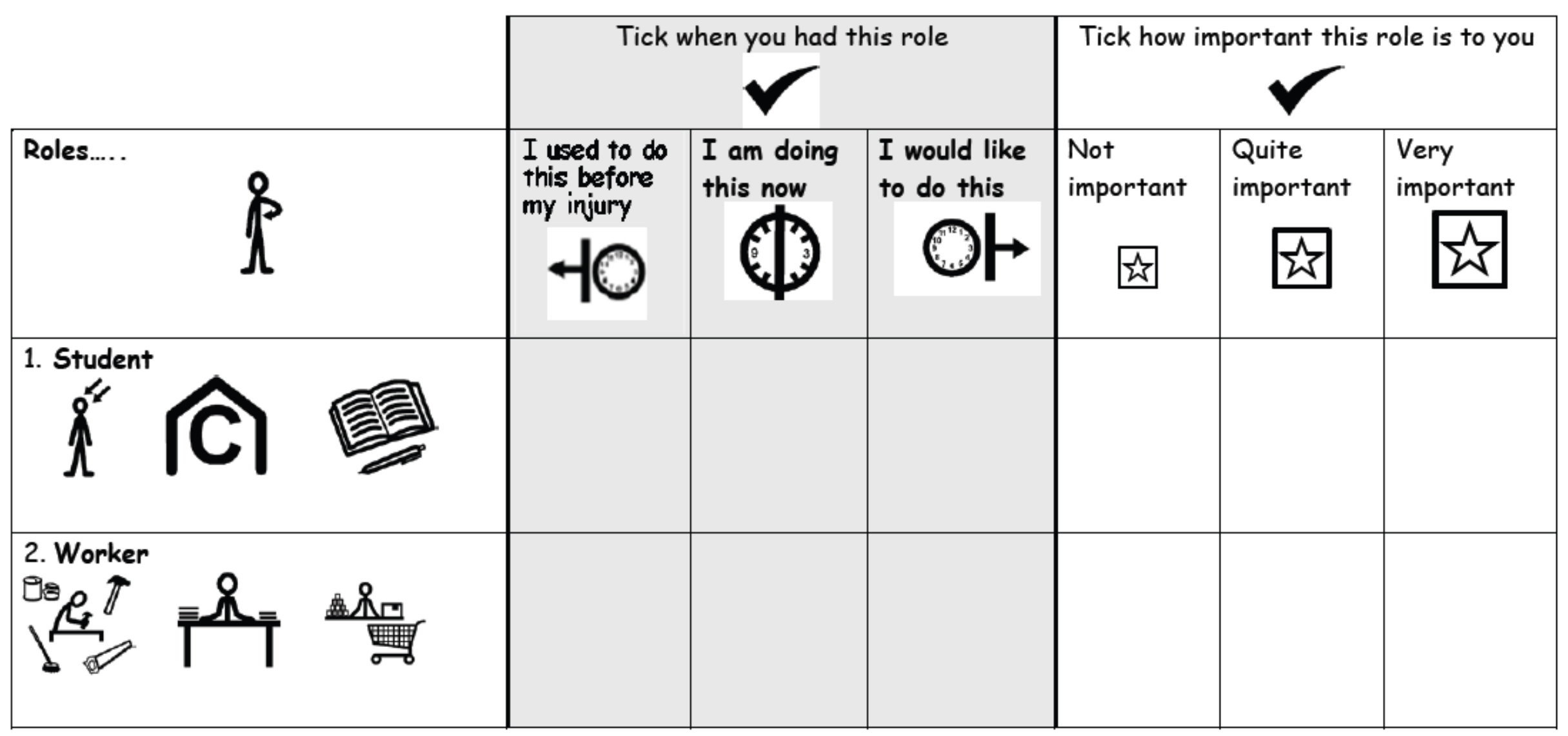




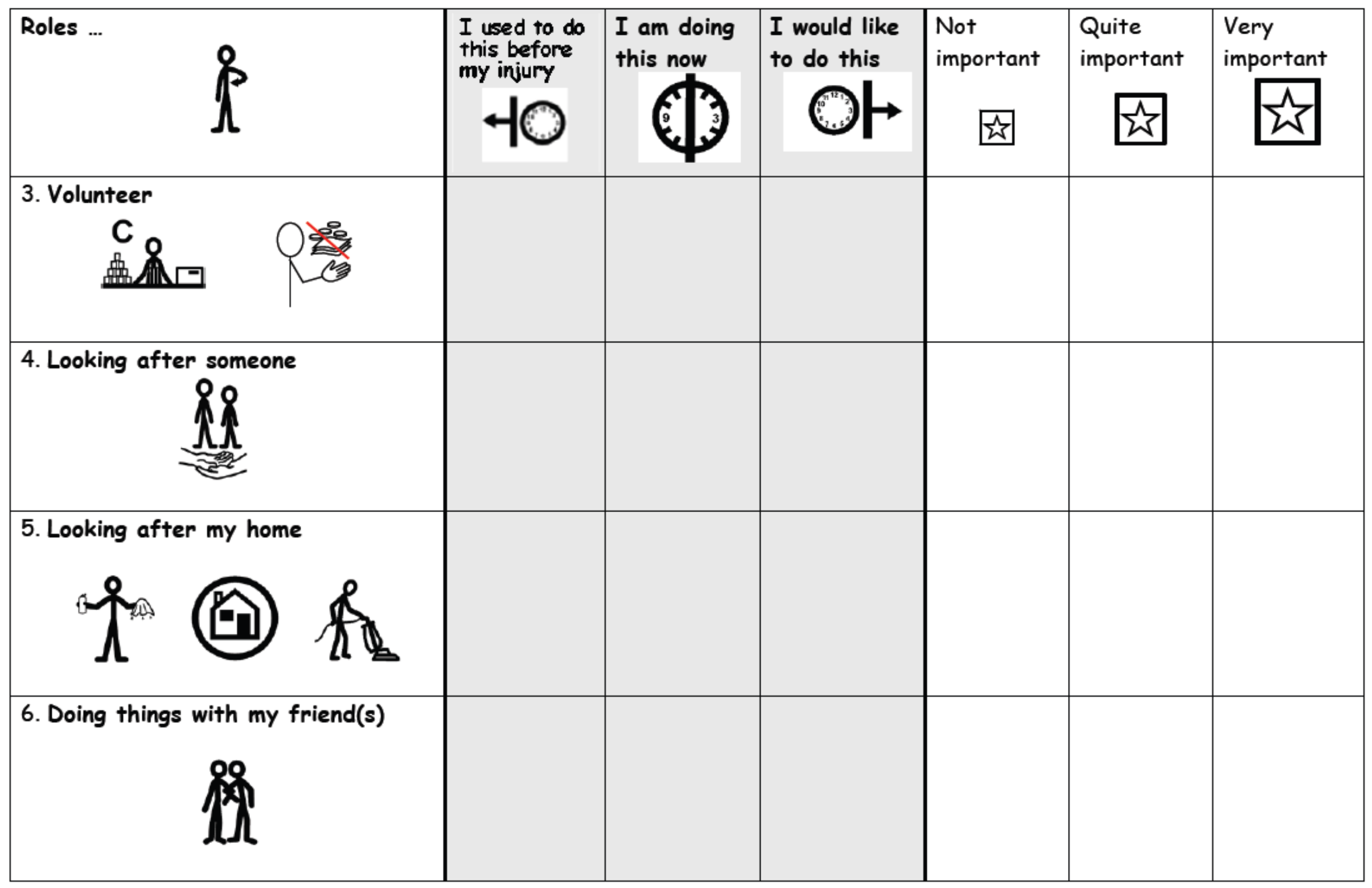




\begin{tabular}{|l|l|l|l|l|l|}
\hline Roles ... & $\begin{array}{l}\text { I used to do } \\
\text { this before } \\
\text { my injury }\end{array}$ & $\begin{array}{l}\text { I am doing } \\
\text { this now }\end{array}$ & $\begin{array}{l}\text { I would like } \\
\text { to do this }\end{array}$ & $\begin{array}{l}\text { Not } \\
\text { important }\end{array}$ & $\begin{array}{l}\text { Quite } \\
\text { important }\end{array}$ \\
\hline 7. Doing things with my family \\
important
\end{tabular}




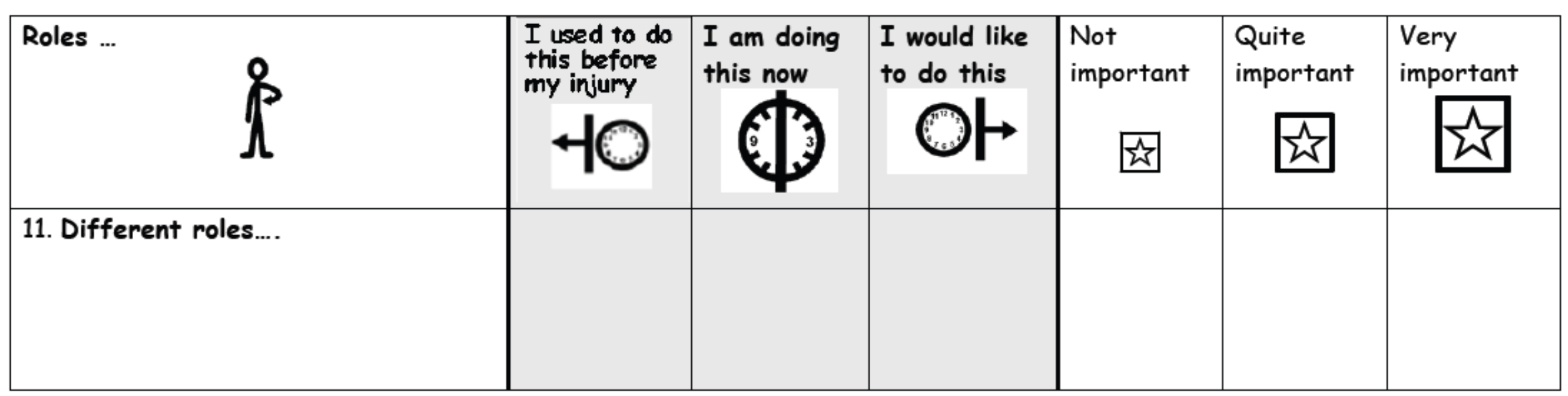

Summary of Role Checklist:

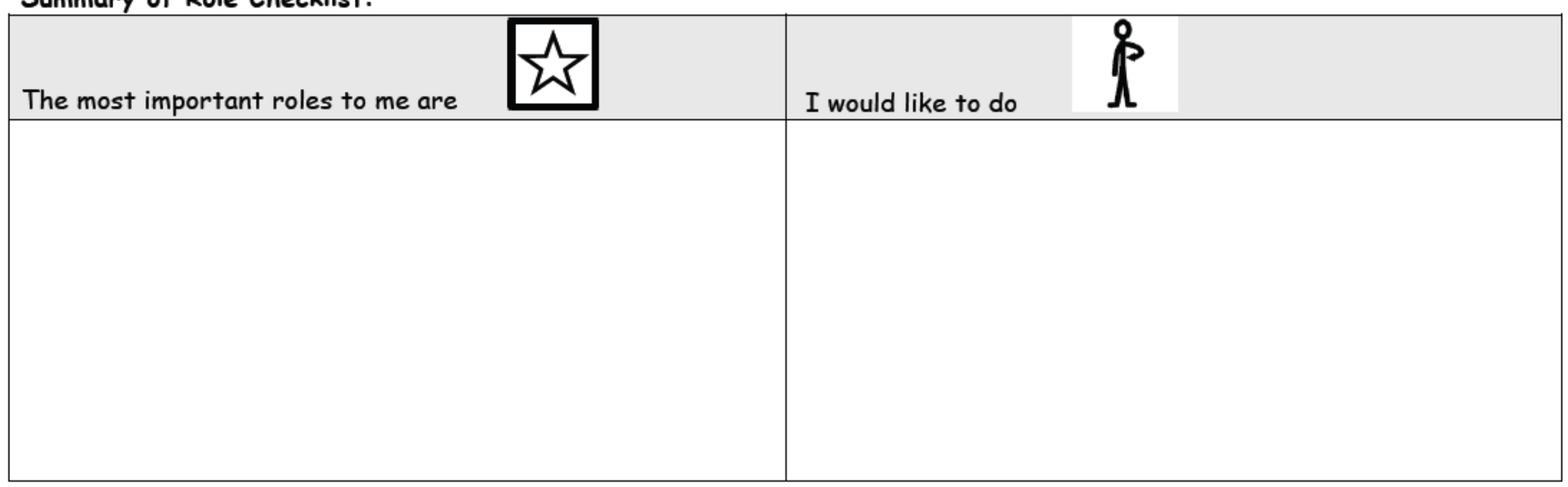

Based on the Role Checklist@ Copyright 1981 and revised 1984, 2006 by Frances Oakley, MS, OTR/L, FAOTA. Adapted by Kim Bogues OT (UK) and Rebecca Wilson OT (UK), with permission. 


\section{Appendix C}

\section{WHOQOL-100}

\section{Instructions}

This questionnaire asks how you feel about your quality of life, health, and other areas of your life. Please answer all the questions. If you are unsure about which response to give to a question, please choose the one that appears most appropriate. This can often be your first response.

Please keep in mind your standards, hopes, pleasures and concerns. We ask that you think about your life in the last two weeks.

For example, thinking about the last two weeks, a question might ask:

How much do you worry about your health?

\begin{tabular}{c|c|c|c|c} 
Not at all & A little & $\begin{array}{c}\text { A moderate } \\
\text { amount }\end{array}$ & Very much & $\begin{array}{c}\text { An extreme } \\
\text { amount }\end{array}$ \\
1 & 2 & 3 & 4 & 5
\end{tabular}

You should circle the number that best fits how much you have worried about your health over the last two weeks. So you would circle the number 4 if you worried about your health "Very much", or circle number 1 if you have worried "Not at all" about your health. Please read each question, assess your feelings, and circle the number on the scale for each question that gives the best answer for you.

Thank you for your help 
The following questions ask about how much you have experienced certain things in the last two weeks, for example, positive feelings such as happiness or contentment. If you have experienced these things an extreme amount circle the number next to "An extreme amount". If you have not experienced these things at all, circle the number next to "Not at all". You should circle one of the numbers in between if you wish to indicate your answer lies somewhere between "Not at all" and "Extremely". Questions refer to the last two weeks.

F1.2 (F1.2.1) ${ }^{*}$ Do you worry about your pain or discomfort?

\begin{tabular}{c|c|c|c|c} 
Not at all & A little & A moderate amount & Very much & An extreme amount \\
1 & 2 & 3 & 4 & 5
\end{tabular}

F1.3 (F1.2.3) How difficult is it for you to handle any pain or discomfort?

\begin{tabular}{c|c|c|c|c} 
Not at all & Slightly & Moderately & Very & Extremely \\
1 & 2 & 3 & 4 & 5
\end{tabular}

F1.4 (F1.2.5)To what extent do you feel that (physical) pain prevents you from doing what you need to do?
Not at all
A little
2
A moderate amount
Very much
An extreme amoun
1
3
4
5

F2.2(F2.1.3)How easily do you get tired?

\begin{tabular}{c|c|c|c|c} 
Not at all & Slightly & Moderately & Very & Extremely \\
1 & 2 & 3 & 4 & 5
\end{tabular}

F2.4 (F2.2.4)How much are you bothered by fatigue?

\begin{tabular}{l|l|l|l|l} 
Not at all & Slightly & Moderately & Very & Extremely \\
1 & 2 & 3 & 4 & 5
\end{tabular}

F3.2 (F4.1.3)Do you have any difficulties with sleeping?
None at all
A little
2
A moderate amount
3
Very much
4
An extreme amount
1
3
5
F3.4 (F4.2.3)How much do any sleep problems worry you?
\begin{tabular}{l|l|l|l|l} 
Not at all & A little & A moderate amount & Very much & An extreme amount \\
1 & 2 & 3 & 4 & 5
\end{tabular}

F4.1 (F6.1.2)How much do you enjoy life? 


\begin{tabular}{c|c|c|c|c} 
Not at all & A little & A moderate amount & Very much & An extreme amount \\
1 & 2 & 3 & 4 & 5 \\
\hline
\end{tabular}

WHOQOL-100 FOR FIELD TRIALS

$\mathrm{MNH} / \mathrm{PSF}$ /95.1.D .Rev.1

Page 4

F4.3 (F6.1.4) How positive do you feel about the future?

\begin{tabular}{c|c|c|c|c} 
Not at all & Slightly & Moderately & Very & Extremely \\
1 & 2 & 3 & 4
\end{tabular}

F4.4 (F6.1.6) How much do you experience positive feelings in your life?

\begin{tabular}{c|c|c|c|c} 
Not at all & A little & A moderate amount & Very much & An extreme amount \\
1 & 2 & 3 & 4
\end{tabular}

F5.3 (F7.1.6) How well are you able to concentrate?

\begin{tabular}{c|c|c|c|c} 
Not at all & Slightly & Moderately & Very well & Extremely \\
1 & 2 & 3 & 4 & 5
\end{tabular}

F6.1 (F8.1.1) How much do you value yourself?

\begin{tabular}{c|c|c|c|c} 
Not at all & A little & A moderate amount & Very much & An extreme amount \\
1 & 2 & 3 & 4 & 5
\end{tabular}

F6.2 (F8.1.3) How much confidence do you have in yourself?

\begin{tabular}{c|c|c|c|c} 
Not at all & A little & A moderate amount & Very much & An extreme amount \\
1 & 2 & 3 & 4
\end{tabular}

F7.2 (F9.1.3) Do you feel inhibited by your looks?

\begin{tabular}{c|c|c|c|c} 
Not at all & Slightly & Moderately & Very much & Extremely \\
1 & 2 & 3 & 4 & 5
\end{tabular}

F7.3 (F9.1.4) Is there any part of your appearance which makes you feel uncomfortable?

\begin{tabular}{c|c|c|c|c} 
Not at all & A little & A moderate amount & Very much & An extreme amount \\
1 & 2 & 3 & 4 & 5
\end{tabular}

F8.2 (F10.1.3) How worried do you feel?
Not at all
Slightly
2
Moderately
3
Very
4
Extremely
5

F8.3 (F10.2.2) How much do any feelings of sadness or depression interfere with your everyday functioning?

\begin{tabular}{c|c|c|c|c} 
Not at all & A little & A moderate amount & Very much & An extreme amount \\
1 & 2 & 3 & 4 & 5
\end{tabular}

F8.4 (F10.2.3) How much do any feelings of depression bother you?

\begin{tabular}{c|c|c|c|c} 
Not at all & A little & A moderate amount & Very much & An extreme amount \\
1 & 2 & 3 & 4
\end{tabular}

F10.2 (F12.1.3)To what extent do you have difficulty in performing your routine activities?
Not at all
A little
A moderate amount
Very much
An extreme amount 3 5 
F10.4 (F12.2.4) How much are you bothered by any limitations in performing everyday living activities?

\begin{tabular}{c|c|c|c|c} 
Not at all & A little & A moderate amount & Very much & An extreme amount \\
1 & 2 & 3 & 4 & 5
\end{tabular}

F11.2 (F13.1.3) How much do you need any medication to function in your daily life?

\begin{tabular}{c|c|c|c|c} 
Not at all & A little & A moderate amount & Very much & An extreme amount \\
1 & 2 & 3 & 4 & 5
\end{tabular}

F11.3 (F13.1.4) How much do you need any medical treatment to function in your daily life?

\begin{tabular}{c|c|c|c|c} 
Not at all & A little & A moderate amount & Very much & An extreme amount \\
1 & 2 & 3 & 4 & 5
\end{tabular}

F11.4 (F13.2.2) To what extent does your quality of life depend on the use of medical substances or medical aids?

\begin{tabular}{c|c|c|c|c} 
Not at all & A little & A moderate amount & Very much & An extreme amount \\
1 & 2 & 3 & 4 & 5
\end{tabular}

F13.1 (F17.1.3) How alone do you feel in your life?

\begin{tabular}{c|c|c|c|c} 
Not at all & Slightly & Moderately & Very much & Extremely \\
1 & 2 & 3 & 4 & 5
\end{tabular}

F15.2 (F3.1.2) How well are your sexual needs fulfilled?

\begin{tabular}{c|c|c|c|c} 
Not at all & Slightly & Moderately & Very much & Extremely \\
1 & 2 & 3 & 4 & 5
\end{tabular}

F15.4 (F3.2.3) Are you bothered by any difficulties in your sex life

\begin{tabular}{c|c|c|c|c} 
Not at all & Slightly & Moderately & Very & Extremely \\
1 & 2 & 3 & 4 & 5
\end{tabular}

F16.1 (F20.1.2) How safe do you feel in your daily life?

\begin{tabular}{c|c|c|c|c} 
Not at all & Slightly & Moderately & Very & Extremely \\
1 & 2 & 3 & 4 & 5
\end{tabular}

F16.2 (F20.1.3 ) Do you feel you are living in a safe and secure environment?

\begin{tabular}{c|c|c|c|c} 
Not at all & Slightly & Moderately & Very much & Extremely \\
1 & 2 & 3 & 4 & 5
\end{tabular}

F16.3 (F20.2.2) How much do you worry about your safety and security?

\begin{tabular}{c|c|c|c|c} 
Not at all & A little & A moderate amount & Very much & An extreme amount \\
1 & 2 & 3 & 4 & 5
\end{tabular}


MNH /PSF /95.1.D .Rev.1

Page 6

F17.1 (F21.1.1) How comfortable is the place where you live?

Not at all

1 Slightly
2
Moderately
3
Very
4

Extremely

5

F17.4 (F21.2.4)How much do you like it where you live?
Not at all
A little
A moderate amount
Very much
An extreme amount
1
2
3
4
5

F18.2 (F23.1.5) Do you have financial difficulties?

\begin{tabular}{c|c|c|c|c} 
Not at all & A little & A moderate amount & Very much & An extreme amount \\
1 & 2 & 3 & 4 & 5
\end{tabular}

F18.4 (F23.2.4) How much do you worry about money?

Not at all

1
A little 2
A moderate amount
Very much

4
An extreme amount 5

F19.1 (F24.1.1) How easily are you able to get good medical care?

Not at all

1
Slightly

2
Moderately 3
Very
4

$\mid \begin{gathered}\text { Extremely } \\ 5\end{gathered}$

F21.3 (F26.2.2) How much do you enjoy your free time?

\begin{tabular}{c|c|c|c|c} 
Not at all & A little & Moderately & Very much & An extreme amount \\
1 & 2 & 3 & 4 & 5
\end{tabular}

*F22.1 (F27.1.2) How healthy is your physical environment?

\begin{tabular}{c|c|c|c|c} 
Not at all & Slightly & Moderately & Very & Extremely \\
1 & 2 & 3 & 4 & 5
\end{tabular}

F22.2 (F27.2.4) How concerned are you with the noise in the area you live in?

\begin{tabular}{c|c|c|c|c} 
Not at all & A little & Moderately & Very much & An extreme amount \\
1 & 2 & 3 & 4 & 5
\end{tabular}

F23.2 (F28.1.4) To what extent do you have problems with transport?

\begin{tabular}{c|c|c|c|c} 
Not at all & A little & A moderate amount & Very much & An extreme amount \\
1 & 2 & 3 & 4 & 5
\end{tabular}

F23.4 (F28.2.3) How much do difficulties with transport restrict your life?

$$
\text { Not at all }
$$$$
1
$$
A little
2

A moderate amount

3
Very much

4 An extreme amount 
The following questions ask about how completely you experience or were able to do certain things in the last two weeks, for example activities of daily living such as washing, dressing or eating. If you have been able to do these things completely, circle the number next to "Completely". If you have not been able to do these things at all, circle the number next to "Not at all". You should circle one of the numbers in between if you wish to indicate your answer lies somewhere between "Not at all" and "Completely". Questions refer to the last two weeks.

F2.1 (F2.1.1) Do you have enough energy for everyday life?
Not at all

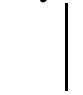
A little
Moderately
3
Mostly
4
Completely

F7.1 (F9.1.2) Are you able to accept your bodily appearance?

Not at all

A little

Moderately

Mostly
4

Completely

$$
1
$$

2

3

5

F10.1 (F12.1.1)To what extent are you able to carry out your daily activities?
Not at all
A little
Moderately
Mostly
Completely
1
2
3
4
5

F11.1 (F13.1.1)How dependent are you on medications?

Not at all

1
A little

2
Moderately

3

Mostly
4

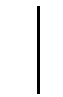

Completely 5

F14.1 (F18.1.2)Do you get the kind of support from others that you need?<smiles>[Mg][Mg]</smiles>

A little

2

$\underset{3}{\text { Moderately }}$

Mostly

4

Completely 5

F14.2 (F18.1.5)To what extent can you count on your friends when you need them?

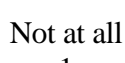

A little

2

Moderately

Mostly

Completely

1

F17.2 (F21.1.2)To what degree does the quality of your home meet your needs?

Not at al

1
A little
2
Moderately

3
Mostly

4
Completely 5

F18.1 (F23.1.1)Have you enough money to meet your needs?

Not at all

A little

2

Moderately
3

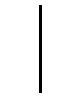

Mostly

4

Completely 5

F20.1 (F25.1.1)How available to you is the information that you need in your day-to-day life?

Not at all

1
A little
Moderately

3
Mostly

4 
WHOQOL-100 FOR FIELD TRIALS

MNH7PSF795.1.D.Rev.1

Page 8

F20.2 (F25.1.2) To what extent do you have opportunities for acquiring the information that you feel you need?

\begin{tabular}{c|c|c|c|c} 
Not at all & A little & Moderately & Mostly & Completely \\
1 & 2 & 3 & 4 & 5
\end{tabular}

F21.1 (F26.1.2)To what extent do you have the opportunity for leisure activities?

Not at all

1
A little
2
Moderately 3
Mostly
4
Completely 5

F21.2 (F26.1.3)How much are you able to relax and enjoy yourself?

Not at all

1
A little
2
Moderately 3
Mostly

4

Completely 5

F23.1 (F28.1.2)To what extent do you have adequate means of transport?

Not at all 1
A little

2
Moderately

3
Mostly
Completely 5 
The following questions ask you to say how satisfied, happy or good you have felt about various aspects of your life over the last two weeks . For example, about your family life or the energy that you have. Decide how satisfied or dissatisfied you are with each aspect of your life and circle the number that best fits how you feel about this. Questions refer to the last two weeks.

G2 (G2.1) How satisfied are you with the quality of your life?

\begin{tabular}{c|c|c|c|c} 
Very dissatisfied & Dissatisfied & Neither satisfied nor & Satisfied & Very satisfied \\
1 & 2 & dissatisfied & 4
\end{tabular}

G3 (G2.2) In general, how satisfied are you with your life?

Very dissatisfied

1

$\mid$

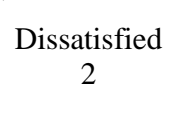

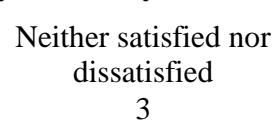

Neither satisfied nor dissatisfied 3

Satisfied

4

Very satisfied 5

G4 (G2.3) How satisfied are you with your health?

Very dissatisfied

Dissatisfied 2
Neither satisfied nor dissatisfied 3
Satisfied 4

Very satisfied 5

F2.3 (F2.2.1) How satisfied are you with the energy that you have?

Very dissatisfied 1

F3.3 (F4.2.2) How satisfied are you with your sleep?

F3.3 (F4.2.2) How satisfied are you with your sleep?

Dissatisfied 2 $\mid$

Neither satisfied nor dissatisfied 3
Very dissatisfied Dissatisfied
2
Neither satisfied nor dissatisfied 3
Satisfied
4

Very satisfied 5

Very satisfied 5

F5.2 (F7.2.1) How satisfied are you with your ability to learn new information?

Very dissatisfied 1
Dissatisfied
2
Neither satisfied nor dissatisfied 3
Satisfied

4
Very satisfied 5

F5.4 (F7.2.3) How satisfied are you with your ability to make decisions?

Very dissatisfied

Dissatisfied 2
Neither satisfied nor dissatisfied 3
Satisfied 4

Very satisfied 5

F6.3 (F8.2.1) How satisfied are you with yourself?

Very dissatisfied
Dissatisfied
2 Neither satisfied nor
dissatisfied
Satisfied 4
Very satisfied 5 
Page 10

F6.4 (F8.2.2) How satisfied are you with your abilities?

\begin{tabular}{c|c|c|c|c} 
Very dissatisfied & Dissatisfied & Neither satisfied nor & Satisfied & Very satisfied \\
1 & 2 & dissatisfied & 4 & 5
\end{tabular}

F7.4 (F9.2.3) How satisfied are you with the way your body looks?

\begin{tabular}{c|c|c|c|c} 
Very dissatisfied & Dissatisfied & Neither satisfied nor & Satisfied & Very satisfied \\
1 & 2 & dissatisfied & 4 & 5
\end{tabular}

F10.3 (F12.2.3)How satisfied are you with your ability to perform your daily living activities?

Very dissatisfied

1
Dissatisfied
2
Neither satisfied nor
dissatisfied
3
Satisfied
4
Very satisfied 5

F13.3 (F17.2.3)How satisfied are you with your personal relationships?

Very dissatisfied
Dissatisfied 2
Neither satisfied nor dissatisfied 3
Satisfied 4 Very satisfied 5

F15.3 (F3.2.1) How satisfied are you with your sex life?
Very dissatisfied 1 Dissatisfied
2<smiles>C1CCCCC1</smiles>
Neither satisfied nor dissatisfied 3

Satisfied
4

Very satisfied 5

F14.3 (F18.2.2)How satisfied are you with the support you get from your family?

Very dissatisfied Dissatisfied
2
Neither satisfied nor
dissatisfied 3
Satisfied 4
Very satisfied 5

F14.4 (F18.2.5)How satisfied are you with the support you get from your friends?

Very dissatisfied

1
Dissatisfied 2
Neither satisfied nor dissatisfied 3
Satisfied 4
Very satisfied 5

F13.4 (F19.2.1)How satisfied are you with your ability to provide for or support others?

Very dissatisfied

1
Dissatisfied 2
Neither satisfied nor dissatisfied 3
Satisfied 4
Very satisfied 5

F16.4 (F20.2.3)How satisfied are you with your physical safety and security?
Dissatisfied
2
Neither satisfied nor dissatisfied
Satisfied 4
Very satisfied 5 
F17.3 (F21.2.2)How satisfied are you with the conditions of your living place?

\begin{tabular}{c|c|c|c|c} 
Very dissatisfied & Dissatisfied & Neither satisfied nor & Satisfied & Very satisfied \\
1 & 2 & dissatisfied & 4 & 5
\end{tabular}

F18.3 (F23.2.3)How satisfied are you with your financial situation?

\begin{tabular}{c|c|c|c|c} 
Very dissatisfied & Dissatisfied & Neither satisfied nor & Satisfied & Very satisfied \\
& 2 & dissatisfied & 4
\end{tabular}

F19.3 (F24.2.1)How satisfied are you with your access to health services?

\begin{tabular}{c|c|c|c|c} 
Very dissatisfied & Dissatisfied & Neither satisfied nor & Satisfied & Very satisfied \\
1 & 2 & dissatisfied & 4 & 5
\end{tabular}

F19.4( F24.2.5)How satisfied are you with the social care services?

\begin{tabular}{c|c|c|c|c} 
Very dissatisfied & Dissatisfied & Neither satisfied nor & Satisfied & Very satisfied \\
1 & 2 & dissatisfied & 4 & 5
\end{tabular}

F20.3 (F25.2.1)How satisfied are you with your opportunities for acquiring new skills?

\begin{tabular}{c|c|c|c|c} 
Very dissatisfied & Dissatisfied & Neither satisfied nor & Satisfied & Very satisfied \\
1 & 2 & dissatisfied & 4 & 5
\end{tabular}

F20.4 (F25.2.2)How satisfied are you with your opportunities to learn new information?

\begin{tabular}{c|c|c|c|c} 
Very dissatisfied & Dissatisfied & Neither satisfied nor & Satisfied & Very satisfied \\
& 2 & 3 & 4
\end{tabular}

F21.4 (F26.2.3)How satisfied are you with the way you spend your spare time?
Very dissatisfied
Dissatisfied
2
Neither satisfied nor dissatisfied 3
Satisfied 4
Very satisfied 5

F22.3 (F27.2.1)How satisfied are you with your physical environment (e.g. pollution, climate, noise, attractiveness)?
Very dissatisfied
1
Dissatisfied
2
Neither satisfied nor dissatisfied
Satisfied 4
Very satisfied 3

F22.4 (F27.2.3)How satisfied are you with the climate of the place where you live?

Very dissatisfied
1

Dissatisfied
Neither satisfied nor dissatisfied


MNH/PSF/95.1.D.Rev.1

Page 12

F23.3 (F28.2.2)How satisfied are you with your transport?

Very dissatisfied 1 Dissatisfied
2

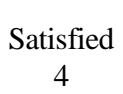

Very satisfied 5

F13.2 (F17.2.1)Do you feel happy about your relationship with your family members?

Very unhappy 1
Unhappy

2
Neither happy nor unhappy $\underset{4}{\text { Happy }}$

\section{?e?}

G1 (G1.1) How would you rate your quality of life? Very poor
1 3
Neither poor nor good

\begin{tabular}{c|c} 
Good & Very good \\
4 & 5
\end{tabular}

F15.1 (F3.1.1) How would you rate your sex life?
Very poor
Poor
Neither poor nor good
3
Good
Very good

Very happy 5

F3.1 (F4.1.1) How well do you sleep?
Very poor

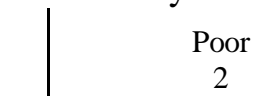
2
Neither poor nor good
3
Good
4
Very good 5

F5.1 (F7.1.3) How would you rate your memory?
Very poor
Poor
2
Neither poor nor good
3

Good
4
Very good 5

F19.2 (F24.1.5)How would you rate the quality of social services available to you?

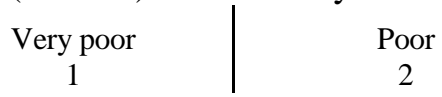

Neither poor nor good

3

Good
4

Very good 
The following questions refer to how often you have felt or experienced certain things, for example the support of your family or friends or negative experiences such as feeling unsafe. If you have not experienced these things at all in the last two weeks, circle the number next to the response "never". If you have experienced these things, decide how often and circle the appropriate number. So for example if you have experienced pain all the time in the last two weeks circle the number next to "Always". Questions refer to the last two weeks.

F1.1 (F1.1.1) How often do you suffer (physical) pain?

Never

1

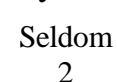

2
Quite often

3
Very often

Always

5

F4.2 (F6.1.3) Do you generally feel content?

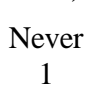

Quite often 3
Very often 4
Always

5

F8.1 (F10.1.2) How often do you have negative feelings, such as blue mood, despair, anxiety, depression?

$$
\text { Never }
$$

1

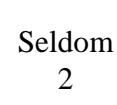

Quite often 3
Very often 4
Always 
WHOQOL-100 FOR FIELD TRIAL

$\mathrm{MNH} / \mathrm{PSF} /$ 95.1.D.Rev.1

Page 14

The following questions refer to any "work" that you do. Work here means any major activity that you do. This includes voluntary work, studying full-time, taking care of the home, taking care of children, paid work or unpaid work. So work, as it is used here, means the activities you feel take up a major part of your time and energy. Questions refer to the last two weeks.

F12.1 (F16.1.1)Are you able to work?

\begin{tabular}{c|c|c|c|c} 
Not at all & A little & Moderately & Mostly & Completely \\
1 & 2 & 3 & 4 & 5
\end{tabular}

F12.2 (F16.1.2)Do you feel able to carry out your duties?

Not at all 1
A little 2
Moderately 3

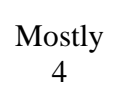

Completely

F12.4 (F16.2.1)How satisfied are you with your capacity for work?

Very dissatisfied 1

$$
\begin{gathered}
\text { Dissatisfied } \\
2
\end{gathered}
$$

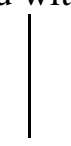

Satisfied
4 3

Neither satisfied
Very satisfied 5

F12.3 (F16.1.3)How would you rate your ability to work?

Very poor

1
Poor

2
Neither poor nor good
Good
4

Very good 
The next few questions ask about how well you were able to move around, in the last two weeks. This refers to your physical ability to move your body in such a way as to allow you to move about and do the things you would like to do, as well as the things that you need to do.

F9.1 (F11.1.1) How well are you able to get around?

F9.3 (F11.2.2) How much do any difficulties in mobility bother you?

\begin{tabular}{c|c|c|c|c} 
Not at all & A little & A moderate amount & Very much & An extreme amount \\
1 & 2 & 3 & 4 & 5
\end{tabular}

F9.4 (F11.2.3) To what extent do any difficulties in movement affect your way of life?

\begin{tabular}{c|c|c|c|c} 
Not at all & A little & A moderate amount & Very much & An extreme amount \\
1 & 2 & 3 & 4 & 5
\end{tabular}

F9.2 (F11.2.1) How satisfied are you with your ability to move around?

\begin{tabular}{c|c|c|c|c} 
Very dissatisfied & Dissatisfied & Neither satisfied nor & Satisfied & Very satisfied \\
1 & 2 & dissatisfied & 4 & 5
\end{tabular}


WHOQOL-100 FOR FIELD TRIALS

MNH/PSF/95.1.D.Rev.1

Page 16

The following few questions are concerned with your personal beliefs, and how these affect your quality of life. These questions refer to religion, spirituality and any other beliefs you may hold. Once again these questions refer to the last two weeks.

F24.1 (F29.1.1)Do your personal beliefs give meaning to your life?
Not at all
A little
2
A moderate amount
Very much
An extreme amount$$
1
$$
3
5

F24.2 (F29.1.3)To what extent do you feel your life to be meaningful?
Not at all
A little
A moderate amount
Very much
4
An extreme amount
5
1
3

2

F24.3 (F29.2.2)To what extent do your personal beliefs give you the strength to face difficulties?
Not at all
A little
2
A moderate amount
Very much
An extreme amount

F24.4 (F29.2.3)To what extent do your personal beliefs help you to understand difficulties in life?

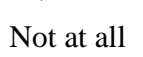

1
A little

2
A moderate amount 3
Very much

4

An extreme amount 5 


\title{
ABOUT YOU
}

What is your gender?

Male

Female

What is your age?

What is highest education you received?

$$
\begin{gathered}
\text { Primary school } \\
\text { Secondary school } \\
\text { University } \\
\text { Post-graduate }
\end{gathered}
$$

What is your marital status?

$$
\begin{gathered}
\text { Single } \\
\text { Married } \\
\text { Living as married } \\
\text { Separated } \\
\text { Divorced } \\
\text { Widowed }
\end{gathered}
$$

How is your health? (G1.2)**

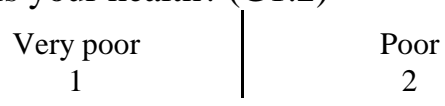

What health problems do you have at the moment? (TICK NEXT TO THOSE THAT APPLY TO YOU)

\author{
Heart trouble \\ High blood pressure \\ Arthritis or Rheumatism \\ Cancer \\ Emphysema or chronic bronchitis \\ Diabetes \\ A cataract \\ Stroke \\ Broken or fractured bone \\ Chronic nervous or emotional problems \\ Chronic foot trouble (bunions, ingrowing toenails) \\ Rectal growth or rectal bleeding
}


CHANGE IN LIFE ROLE IN OLDER ADULTS AFTER INJURY

Parkinson's disease

Other (please describe)

Are you currently ill?

If yes, what is your diagnosis?

Do you have any comments about the questionnaire? 
CHANGE IN LIFE ROLE IN OLDER ADULTS AFTER INJURY

THANK YOU FOR YOUR HELP 


\section{Appendix D}

Change in Life Roles in Older Adults following Injury: Questions for Semi-Structured

\section{Interview}

- Let participant know;

-What we will do today

- They can skip questions if they would like to

-If fatigue is an issue let me know

- I am noting answers verbatim as we go so may get you to repeat something if needs be

\section{Injury Information}

1. What type of injury do you have?

2. What was the classification of your injury? (Mild/Moderate/Severe

-If unsure then ask about LOC and PTA

3. When did you injury occur?

4. How did your injury occur?

5. Age at time of injury?

6. Age now?

\section{Perceptions of support and barriers}

7. What rehabilitative input did you receive after your injury?

8. How supported did you feel throughout your rehabilitation and why?

9. What barriers to you recovery did you perceive?

10. How does pain impact on you participating in activities you would have participated in before your injury?

\section{Satisfaction with Life Roles}

"I have your questionaiires here and we will run through your answers. What I'd like you to

\begin{tabular}{|c|c|c|c|c|}
\hline Very & Dissatisfied & Neither satisfied & Satisfied & Very satisfied \\
\hline dissatisfied & 2 & nor dissatisfied & 4 & 5 \\
\hline 1 & & 3 & & \\
\hline
\end{tabular}


is rate your satisfaction with your ability to perform these roles on a scale of $1-5$ with 1

being the worst and 5 being the best". Read off scale and check understanding.

1. Describe your satisfaction with your ability to perform the roles you currently participate in (last 7 days) Now; then before your injury
a. Worker:
b. Volunteer:
c. Looking after someone:
d. Looking after my home:
e. Doing things with friends:
f. Doing things with family:
g. Doing things with my church :
h. Having hobbies: photography biking,
i. Doing things with wider groups:

2. How satisfied are you with your life roles after your injury?

3. How satisfied with your life roles were you before your injury?

\section{Daily Activities}

4. What daily activities have you performed over the last 7 days and describe satisfaction of your ability to perform these? What impacts on these?
a. Use of telephone/other communications:
b. Shopping :
c. Food preparation and clean up:
d. Housekeeping:
e. Laundry:
f. Transportation within the community:
g. Taking medications as prescribed: -
h. Managing money:
i. Care of others:-
j. Other: 


\section{Appendix E}

Department of Psychology

Telephone: +64 33642987 Ext: 7884

Email: katie.dainter@pg.canterbury.ac.nz

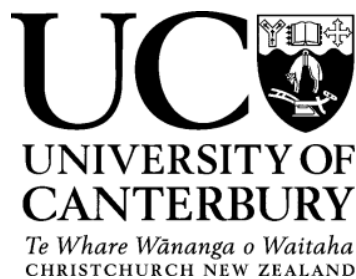

\section{Change in Life Roles in Older Adults following injury Information sheet for participants with an injury}

My name is Katie Dainter, and I am doing a Master of Science Thesis project looking at changes in life roles and quality of life after injury in older adults compared to those without an injury event. This study is investigating whether older adults who have sustained a traumatic brain injury are able to recover enough whereby they are able to continue with the life roles they had before their injury and whether this impacts on their perceived quality of life. To do this we are comparing older adults who have had a traumatic brain injury to older adults who have broken a bone, to see if their rehabilitation and subsequent recovery is similar, and whether this impacts on the life roles and quality of life. Similarly, we are also comparing older adults who have had an injury to older adults who have not had an injury, to see if there are differences in daily activities performed, role change and satisfaction with life.

Your involvement in this project will be completing two questionnaires and participating in a semistructured interview. Questions will focus on overall quality of life, your participation in life roles, some details surrounding your injury and your experiences of your rehabilitation. In total your participation should take approximately one hour and 30 minutes. You will be posted the questionnaires for you to complete in your own home, which you will then return to the University of Canterbury (postage will be provided). After I have received your questionnaires we will conduct a short interview over the phone and will talk about some of the answers you indicated, such as your satisfaction with your life roles. You will receive a $\$ 10$ fuel or New World voucher for completing your interview. If you agree to participate in the study, you will be asked to complete the consent form to be returned to me with your questionnaires.

You may receive a copy of the project results by contacting the researcher at the conclusion of the project.

Participation is voluntary and you have the right to withdraw at any stage during the interview process without penalty. After the interview process has been completed, it will not be possible to withdraw. If you withdraw, I will remove information relating to you. Whilst answering the questions involved in this interview, you may experience some discomfort or emotional distress due to the personal nature of some of these questions. If this is the case, you do not have to answer any questions you feel uncomfortable answering. A list of support services is provided overleaf, and we encourage you to utilize these should you need to.

The results of the project may be published, but you may be assured of the complete confidentiality of data gathered in this investigation: your identity will not be made public without your prior consent. To ensure anonymity and confidentiality, your identifying details such as name and date of birth will not be used. Your information will be identified by a code number. A master file containing the names and codes of participants will be kept on a password protected computer in a secure office in the Department of Psychology. Your data will be stored in a locked filing cabinet in a secure office. The only people who will have access to this data will be the researcher and Dr Audrey McKinlay and Professor Randolph Grace, who are supervising this study. Your data will be stored for 5 years to 
enable the publication of information resulting from the study. After this the data will be destroyed. A thesis is a public document and will be available through the UC Library.

The project is being carried out as a requirement for a Master of Science by Katie Dainter under the supervision of Dr Audrey McKinlay and Professor Randolph Grace, who can be contacted at audrey.mckinlay@canterbury.ac.nz or randolph.grace@canterbury.ac.nz. They will be pleased to discuss any concerns you may have about participation in the project.

This project has been reviewed and approved by the University of Canterbury Human Ethics Committee, and participants should address any complaints to The Chair, Human Ethics Committee, University of Canterbury, Private Bag 4800, Christchurch (human-ethics@canterbury.ac.nz).

\section{Katie Dainter}

\section{Support Services}

\section{Free Telephone Counselling Services:}

Samaritans: 0800726666

Lifeline: 0800543354

\section{Other contacts:}

Health and Disability Advocacy Service: (03) 3777501

Brain Injury Association for Canterbury/West Coast: (03) 3653262

Citizens Advice Bureau: 0800367222 


\section{Appendix F}

Department of Psychology

Telephone: +64 33642987 Ext: 7884

Email: katie.dainter@pg.canterbury.ac.nz

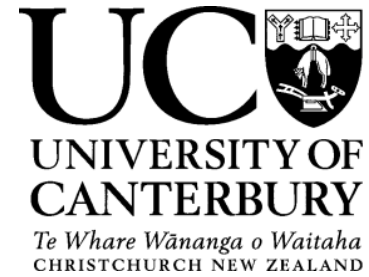

Kia Ora and thank you for participating in this study.

Please read these instructions before completing your questionnaires.

In this questionnaire pack you should find:

1. Information sheet

2. Consent form

3. Receipt of participant incentive form

4. WHOQOL-100 questionnaire

5. Role checklist questionnaire

6. $\$ 10$ voucher (Fuel or New World)

7. Addressed envelope

Before commencing your questionnaires, please ensure that you carefully read your information sheet, consent form and receipt of participant incentive form, that you fully understand each and that you sign where appropriate.

After this, please complete the WHOQOL-100 and role checklist. Instructions for each are attached at the front of the questionnaires. If you feel unsure about any answers, it's best to go with the one that seems most appropriate, which is usually your first answer. If you any questions, or would like some clarification around anything, feel free to get in touch with me, either through email or phone.

When you have completed your forms and questionnaires, please return all forms and questionnaires to me in the pre-addressed envelope. Postage has already been paid for.

After I have received your questionnaire pack, we will arrange a time for a phone call, where we will conduct a short interview talking about some of your answers on the questionnaire.

If you have any questions please don't hesitate to get in touch.

Looking forward to hearing from you,

Katie Dainter

Ph: 0226325543

Email: katie.dainter@pg.canterbury.ac.nz 


\section{Appendix G}

Department of Psychology

Telephone: +64 33642987 ext. 7884

Email: katie.dainter@pg.canterbury.ac.nz

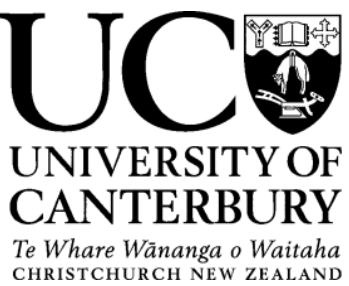

\section{Change in Life Roles in Older Adults following injury Consent Form}

I have been given a full explanation of this project and have had the opportunity to ask questions.

I understand what is required of me if I agree to take part in the research.

I understand that participation is voluntary and I may withdraw at any time without penalty. Withdrawal of participation will also include the withdrawal of any information I have provided should this remain practically achievable.

I understand that any information or opinions I provide will be kept confidential to the researcher, Dr Audrey McKinlay and Professor Randolph Grace, and that any published or reported results will not identify the participants. I understand that a thesis is a public document and will be available through the UC Library.

I understand that all data collected for the study will be kept in locked and secure facilities and/or in password protected electronic form and will be destroyed after five years.

I understand the risks associated with taking part and how they will be managed.

I understand that I am able to receive a report on the findings of the study by contacting the researcher at the conclusion of the project.

I understand that I can contact the researcher Katie Dainter at Katie.dainter@pg.canterbury.ac.nz or supervisors Dr Audrey McKinlay at audrey.mckinlay@ @ canterbury.ac.nz or Professor Randolph Grace at randolph.grace@canterbury.ac.nz for further information. If I have any complaints, I can contact the Chair of the University of Canterbury Human Ethics Committee, Private Bag 4800, Christchurch (humanethics@canterbury.ac.nz)

By signing below, I agree to participate in this research project.

Name:

Signature:

Date:

Please return this form with your questionnaires to the researcher.

Katie Dainter 


\section{Appendix H}

College of Science

Department of Psychology

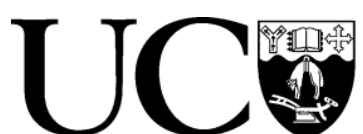

UNIVERSITY OF CANTERBURY

Te Whare Wãnanga o Waitaha

\section{Change in Life Roles in Older Adults following injury Receipt of Participant Incentive}

The University of Canterbury requires an audit trail for any incentives given to research participants. The person named below is conducting the research you have agreed to take part in. Providing your signature below confirms you have incentive listed below. Thank you for participating in this research!

Name of Researcher: Katie Dainter

Voucher amount: $\quad \$ 10$

Voucher type: $\quad$ New World/Fuel (please indicate

By signing below, I confirm I have received my incentive voucher listed above.

Name:

Signature: 


\section{Appendix I}

HUMAN ETHICS COMMITTEE

Secretary, Lynda Griffioen

Email: human-ethics@canterbury.ac.nz

Ref: HEC 2014/22

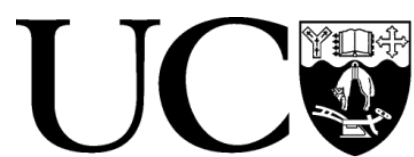

UNIVERSITY OF CANTERBURY

Te Whare Wänanga o Waitaha CHRISTCHURCH NEW ZEALAND

14 May 2014

Katie Dainter

Department of Psychology

UNIVERSITY OF CANTERBURY

Dear Katie

The Human Ethics Committee advises that your research proposal "Change in life roles in older adults following injury" has been considered and approved.

Please note that this approval is subject to the incorporation of the amendments you have provided in your email of 7 May 2014.

Best wishes for your project.

Yours sincerely<smiles>CC(C)CCC1CC2CC3CCCC(C3)C2C1</smiles>

Lindsey MacDonald

\section{Chair}

University of Canterbury Human Ethics Committee 